\title{
Gradients of receptor expression in the macaque cortex
}

\author{
Sean Froudist-Walsh ${ }^{1}$, Ting $\mathrm{Xu}^{2}$, Meiqi Niu ${ }^{3}$, Lucija Rapan ${ }^{3}$, Daniel S. Margulies ${ }^{4}$, \\ Karl Zilles ${ }^{3, *}$, Xiao-Jing Wang ${ }^{1,+}$, Nicola Palomero-Gallagher ${ }^{3,+}$ \\ ${ }^{1}$ Center for Neural Science, New York University, New York, NY, USA \\ ${ }^{2}$ Child Mind Institute, New York, NY, USA \\ ${ }^{3}$ Institute of Neuroscience and Medicine (INM-1), Research Centre Jülich, Jülich, \\ Germany \\ ${ }^{4}$ Integrative Neuroscience and Cognition Center, University of Paris, Paris, \\ France \\ + joint-senior authors \\ * deceased 25 April 2020 \\ Corresponding authors: \\ Nicola Palomero-Gallagher \\ Xiao-Jing Wang \\ Sean Froudist-Walsh \\ Institute of Neuroscience and Medicine (INM-1) \\ Research Centre Jülich \\ Jülich \\ Germany \\ Phone: +49-2461-614790 \\ Fax: +49-2461-612820 \\ n.palomero-gallagher@fz-juelich.de \\ Center for Neural Science \\ New York University \\ New York, NY, \\ USA \\ xjwang@nyu.edu \\ Center for Neural Science \\ New York University \\ New York, NY, \\ USA \\ seanfw@nyu.edu
}




\begin{abstract}
Dynamics and functions of neural circuits depend on synaptic interactions mediated by receptors. Therefore, a comprehensive map of receptor organization is needed to understand how different functions may emerge across distinct cortical regions. Here we use in-vitro receptor autoradiography to measure the density of 14 neurotransmitter receptor types in 109 areas of macaque cortex. We integrate the receptor data with other anatomical, genetic and functional connectivity data into a common cortical space. We uncovered a principal gradient of increasing receptor expression per neuron aligned with cortical hierarchy from early sensory cortex to higher cognitive areas. A second gradient, primarily driven by $5-\mathrm{HT}_{1 \mathrm{~A}}$ receptors, peaks in the anterior and subcallosal cingulate, suggesting that the macaque may be a promising animal model for major depressive disorder. The receptor gradients may enable rapid, reliable information processing in sensory cortical areas and slow, flexible integration of information in higher cognitive areas.
\end{abstract}




\section{Introduction:}

Flexibility is a hallmark of biological intelligence. A key challenge in modern neuroscience is to discover the cellular, molecular and systems architecture that enables the brain to adapt flexibly and appropriately to a rapidly changing world. The creation of nearly complete maps of the brain's connections across species at the macroscopic (Glasser et al., 2016), mesoscopic (Majka et al., 2020; Markov et al., 2014a; Oh et al., 2014) and microscopic levels (Scheffer et al., 2020; White et al., 1986) has been a major achievement. However, connectivity alone is insufficient to explain neural circuit dynamics underlying brain functions, which depend on the type and timescale of synaptic transmission mediated by transmitter receptors. Therefore, connectomic approaches, which are blind to receptor types, may not be sufficient to understand the computational capabilities of the cortex. The systematic mapping of multiple receptor densities across cortex would provide a crucial link between the molecular and systems organization of the cortex, complementing ongoing efforts to map the connectome.

In comparison to rodents, macaques and humans share a very similar regional and laminar receptor profile (Zilles and Palomero-Gallagher, 2017a). Parallel recent advances in in-vivo neuroimaging (Milham et al., 2020, 2018) and mesoscale connectome mapping (Markov et al., 2014a, 2014b, 2013) have increased the translational potential of studies on the macaque brain. Integration of gold-standard neuroanatomy with in-vivo measures of cortical structure and function has great promise to help translation across species and scales of neuroscience, but is still in its infancy (Donahue et al., 2016; Froudist-Walsh et al., 2018, 2020; Hayashi et al., 2020; Rapan et al., 2020; Scholtens et al., 2014; Wang et al., 2020). The mapping of precise receptor and anatomical data to a cortical space that is accessible to neuroimaging researchers could dramatically accelerate our understanding across scales of how the brain works, from the synapse to distributed cognitive networks.

While cortical microcircuits share a canonical organization, their properties vary gradually across the cortex in the form of macroscopic gradients (Wang, 2020). So far, little work has been done to compare gradients of distinct anatomical properties. The seemingly complex connectivity structure of the cortex can be well described by a small number of connectivity gradients (Margulies et al., 2016), with patterns of connectivity smoothly changing across the cortex from early sensory areas to peaks in the higher areas of association cortex. Similar understanding of the brain's large-scale receptor organization is beginning to emerge. In the mouse brain, subcortical neuromodulatory centres have been identified as 'connector hubs', that are well placed to influence interactions between networks (Coletta et al., 2020). Large-scale patterns of receptor expression have been recently described in the human brain (Goulas et al., 2021; Zilles and Palomero-Gallagher, 2017b), but it is not known how the pattern 
of receptor expression may relate to distributed cognitive networks, and the functions they produce.

Here, we measured the density of 14 types of neurotransmitter receptors across 109 areas of macaque cortex. We mapped the data for these 14 receptors, as well as data on neuron density, dendritic tree size, dendritic spines, retrograde tract-tracing of cortical connections and in-vivo estimates of cortical microstructure and functional connectivity onto a common cortical space. We find that the receptor architecture of macaque cortex can be well described by a set of low-dimensional gradients. The principal receptor gradient defines a putative cortical hierarchy. Cortical areas high on the gradient had a higher density of receptors per neuron, more dendritic spines per pyramidal cell, larger dendrites, and a lower $\mathrm{T} 1 \mathrm{w} / \mathrm{T} 2 \mathrm{w}$ ratio, indicative of less myelin. Receptor gradients also aligned with in-vivo functional connectivity gradients, suggesting a possible role for neuromodulatory receptors in shifting activity along cortical hierarchies and between higher cognitive networks.

\section{Results:}

\section{Distributions of 14 receptor types across 109 regions of macaque cortex}

We first analyzed receptor distribution patterns for 14 receptors throughout the macaque brain using in-vitro receptor autoradiography, which enables the quantification of endogenous receptors in the cell membrane through the use of radioactive ligands (Palomero-Gallagher and Zilles, 2018a). Our analysis included three glutamatergic (AMPA, kainate, NMDA), three GABAergic $\left(\mathrm{GABA}_{A}\right.$, $\mathrm{GABA}_{A / B Z}, G A B A_{B}$ ) and eight neuromodulatory (acetylcholine $\mathrm{M}_{1}, \mathrm{M}_{2}, \mathrm{M}_{3}$; serotonin $5-\mathrm{HT}_{1 \mathrm{~A}}, 5-\mathrm{HT}_{2}$, noradrenaline $\alpha_{1}, \alpha_{2}$, dopamine $\mathrm{D}_{1}$ ) receptors. In the raw data, several receptors reached highest densities in primary visual cortex $\left(\mathrm{GABA}_{\mathrm{A}}\right.$, acetylcholine $\mathrm{M}_{2}$, serotonin 5- $\mathrm{HT}_{2}$ ) (Zilles and Palomero-Gallagher, 2017a)(Fig. S1). A distinct set of receptors reached highest densities in parts of the anterior cingulate, including all glutamatergic receptors, $\mathrm{GABA}_{B}$, serotonin 5$\mathrm{HT}_{1 \mathrm{~A}}$, noradrenaline $\alpha_{1}$, and dopamine $\mathrm{D}_{1} . \mathrm{M}_{1}, \mathrm{GABA} / \mathrm{Bz}$ and $\alpha_{2}$ receptors are notable for having high densities in both cingulate cortex and V1. This suggests some shared anatomical patterns of expression across receptors.

For each receptor, except for $5-\mathrm{HT}_{1 \mathrm{~A}}$, the cortical area with the highest density usually contained roughly two to five times as many receptors (per mg protein) as the least dense area (range 1.67-4.7, min 5- $\mathrm{HT}_{2}$, max $\mathrm{M}_{2}$ ). The exception was the $5-\mathrm{HT}_{1 \mathrm{~A}}$ receptor, which reached a peak density of $1185 \mathrm{fmol} / \mathrm{mg}$ protein in area a24'ab of anterior cingulate cortex, over 17 times the density of 5-HT $1 \mathrm{~A}$ receptors in area V1 (Fig S1). The degree to which neurotransmitters affect neural activity depends on the density of receptors on the cell surface of a neuron (Lu et al., 2001). Receptor autoradiography quantifies the receptors in the cell membrane, but is blind to the neuron density. However, the neuron density also varies by a factor of five across macaque cortex (Fig S1). We reasoned that 
what matters functionally is receptor expression level per neuron, hence mapped the receptor data and previously published neuron density data (Collins et al., 2010) to the Yerkes 19 cortical surface (Donahue et al., 2016), and estimated the receptor density per neuron across the cortex for all 14 receptor types (Fig. 1). Notably, although the density of several receptors peaks in V1 in the raw data, this is mostly erased when accounting for neuron density. This suggests that the high density of receptors in V1 is largely due to its exceptionally high neuron density (with the possible exception of the $M_{2}$ receptor). 
bioRxiv preprint doi: https://doi.org/10.1101/2021.02.22.432173; this version posted February 22, 2021. The copyright holder for this preprint (which was not certified by peer review) is the author/funder, who has granted bioRxiv a license to display the preprint in perpetuity. It is made available under aCC-BY-NC 4.0 International license.

A) neuron density area borders on Yerkes19 surface

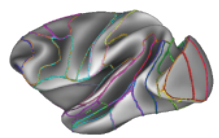

B)

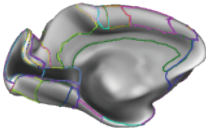

Glutamate

AMPA
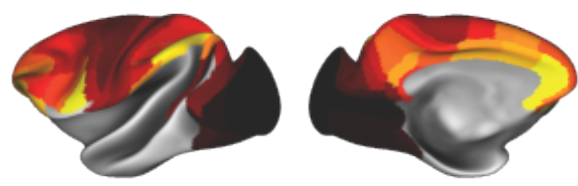

kainate
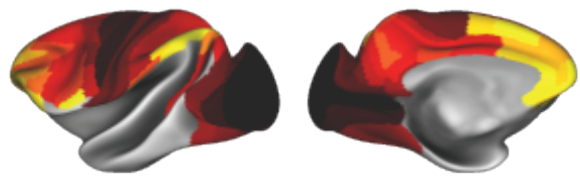

NMDA
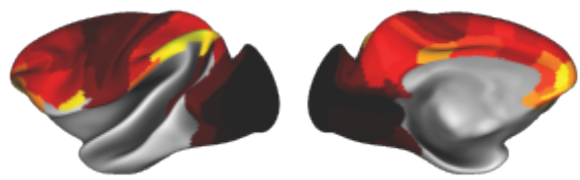

Acetylcholine
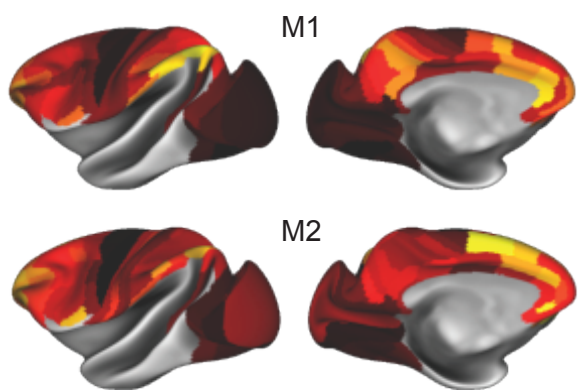

M2
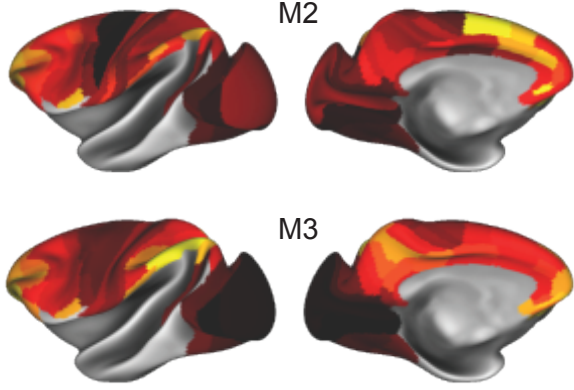

Dopamine

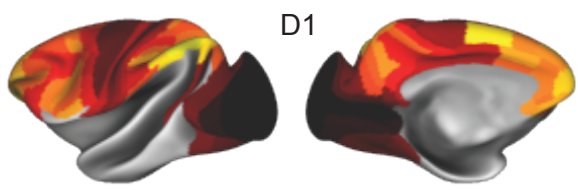

min density neuron density data

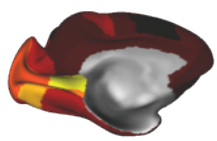

neuron density estimated within Jülich Macaque Brain Atlas borders
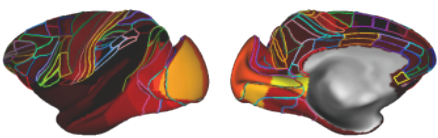

GABA

GABA $_{A}$

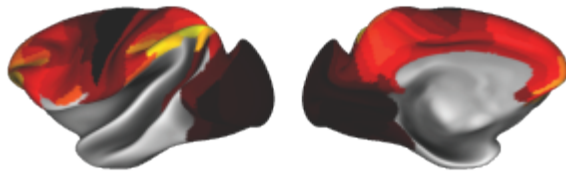

$\mathrm{GABA}_{\mathrm{A}, \mathrm{BZ}}$

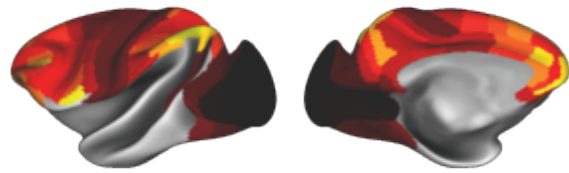

$\mathrm{GABA}_{\mathrm{B}}$

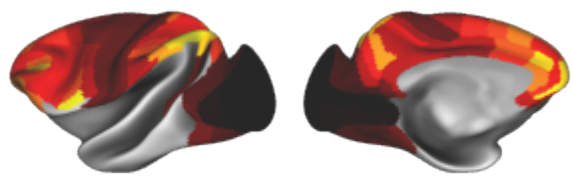

Serotonin
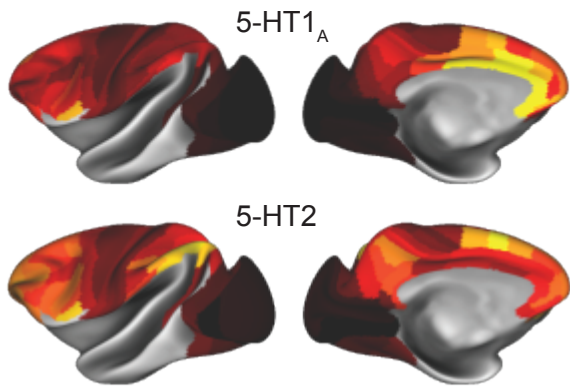

Noradrenaline

$\alpha 1$
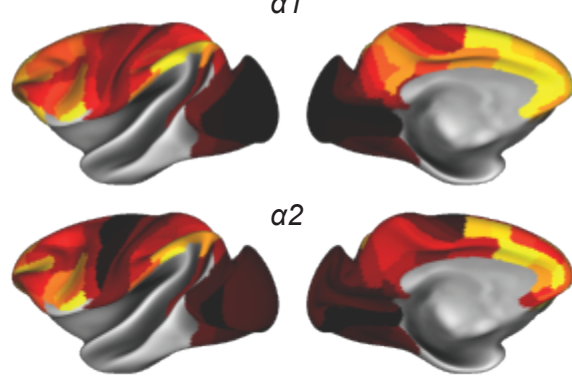

max density

Figure 1. The density of 14 receptors per neuron across macaque cortex. A) Neuron density data from (Collins et al., 2010) was delineated on the cortex and used to normalise receptor data. $B)$ The receptor density per neuron of 14 receptor types assessed with in-vitro receptor autoradiography. 


\section{The principal receptor gradient of macaque cortex}

To identify the principal patterns of spatial variation across receptors, we performed a principal components analysis (PCA) on the receptor density per neuron data. The first principal component (principal receptor gradient), spread from early visual cortex at one end, to association areas of anterior cingulate cortex, orbitofrontal cortex, lateral prefrontal and lateral parietal cortex at the other end. This component alone explained $81 \%$ percent of the variance in the receptor data, with the top five principal components sufficient to explain $95 \%$ (Fig 2A, Fig. S2, PCs1-5 explain $81.2 \%, 6.5 \%, 3.5 \%, 2.4 \%$ and $1.4 \%$ respectively). Projection of the data onto the first two principal components ("receptor space") revealed a differentiation of areas into anatomo-functional clusters (Fig 2B), with visual, somatomotor, premotor, parietal, cingulate, prefrontal and orbitofrontal areas occupying distinct sections of the receptor space.

\section{The density of receptors per neuron increases along the principal receptor gradient}

Receptor fingerprints allow for visualization of the unique pattern of receptors expressed in each cortical area (Geyer et al., 1998; Zilles et al., 2002a). Cortical area V1 (visual cortex), 3al (somatosensory cortex) and 12o (orbitofrontal cortex) lie near the bottom, middle and top of the principal receptor gradient, while occupying similar positions along the secondary gradient. Visualizing the receptor fingerprints of these areas allows us to visualize changes in receptor expression along the principal receptor gradient. The most striking change along the principal receptor gradient was a general increase in the size of the receptor fingerprint, which is indicative of an increase in receptor density per neuron across almost all receptors (Fig 2C). Neurons near the top of the gradient contain on average a 3-4 times higher receptor density than those near the bottom (Fig 2D). The gradient closely tracked total receptors per neuron across brain areas (Fig 2D, $r=0.9953, p=4 \times 10^{-110}$ ). We next investigated how the principal receptor gradient relates to other known macroscopic gradients of anatomical organization. 

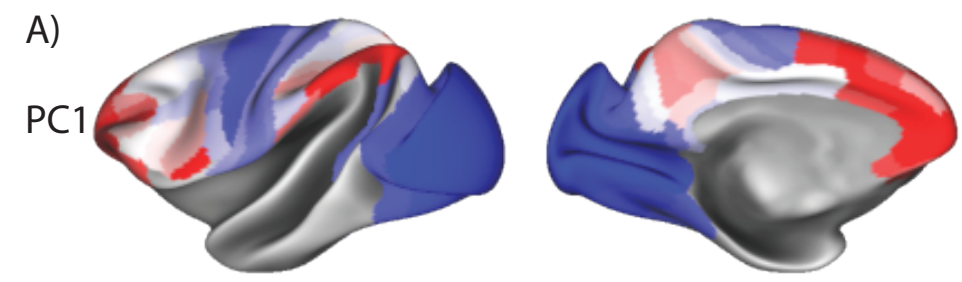

Principal Receptor Gradient
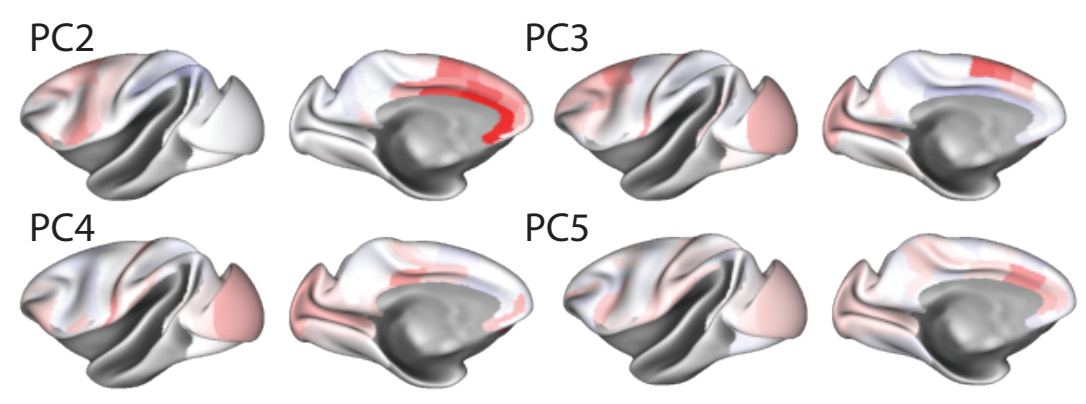

$-7.5$
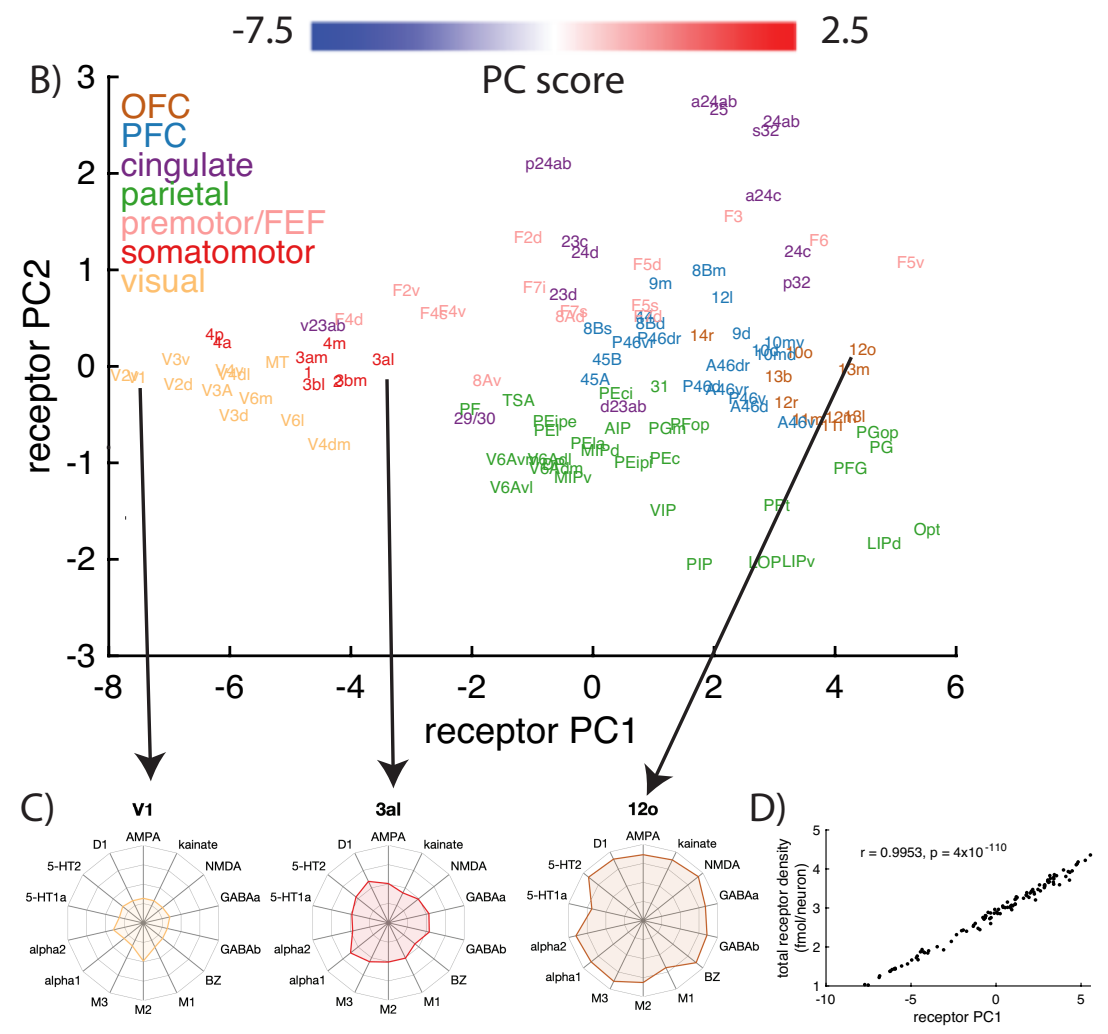

\section{5}

Figure 2. The principal receptor gradient captures total receptor density per neuron across macaque cortex. A) The first five principal components of the receptor per neuron data. B) The projection of brain regions onto the first two principal components of the receptor data ('receptor space'). Brain regions clustered into rough anatomo-functional groups in receptor space. C) The receptor fingerprints of three areas at different points along the first principal component (i.e. the primary receptor gradient). The density of most receptors increases along the gradient, from are V1 to $3 a l$ and again to 120. D) The first principal component closely follows the total receptor density per neuron. 


\section{The principal receptor gradient increases along the cortical hierarchy}

The cortical hierarchy describes an ordering in the cortex from areas that process basic sensory features of stimuli, low in the hierarchy, to areas that receive highly processed information, high in the hierarchy. Feedforward connections (from low to high areas in the hierarchy) tend to emerge from superficial cortical layers, while feedback connections (from high to low areas) tend to emerge from deep cortical layers (Markov et al., 2014b). Based on this knowledge, we recently estimated the cortical hierarchy of 40 cortical areas (Froudist-Walsh et al., 2020) using laminar retrograde tracing data (Felleman and Van Essen, 1991; Markov et al., 2014b). Here, we found a strong positive correlation between the principal receptor gradient and cortical hierarchy $\left(r=0.81, p=8 \times 10^{-8}\right.$, all $p$-values Bonferroni corrected, Fig 3A). As the principal receptor gradient closely tracks the density of receptors per neuron, neurons lower in the cortical hierarchy (which process basic aspects of sensory stimuli) contain a relatively low number of receptors. In contrast, neurons near the top of the hierarchy (which receive multimodal information and contribute to complex cognitive functions) are endowed with a higher density of receptors, which may enable them to act with greater flexibility.

\section{The size of the dendritic tree and number of dendritic spines increases along the principal receptor gradient}

The striking increase in receptor density per neuron along the cortical hierarchy may require the emergence of a special cellular anatomy capable of housing such a high number of receptors. As pyramidal cells receive the vast majority of their synaptic contacts on the dendritic tree (Megías et al., 2001; Spruston, 2008), we investigated whether dendritic properties of neurons varied along the principal receptor gradient. Elston and colleagues measured the size of the dendritic tree and the number of dendritic spines on layer 3 pyramidal cells across dozens of areas of macaque cortex. Based on detailed descriptions and illustrations of the location of injections in those papers (Elston, 2001, 2000, 2000; Elston et al., 2011a, 2011a, 2011b, 2010, 2009, 2005, 1999; Elston and Rockland, 2002; Elston and Rosa, 1998a, 1997, 1998b), we identified the macroanatomic locations for the dendritic analyses on the Yerkes19 cortical surface. This revealed a positive correlation between the principal receptor gradient and dendritic tree size $(r=0.73, p=0.0007$; Fig 3B), and between the principal receptor gradient and the number of dendritic spines per neuron $(r=$ $0.54, p=0.04$, Fig $3 C$ ). Thus, neurons that are higher up the principal receptor gradient contain larger dendritic trees, with more spines. This likely provides the neural real estate required to house a greater number of synaptic connections and receptors. 


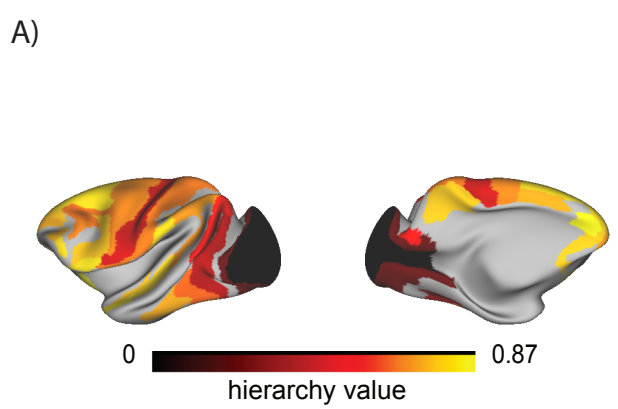

B)
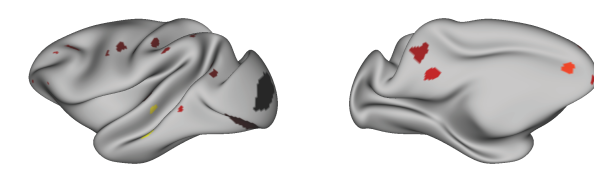

34

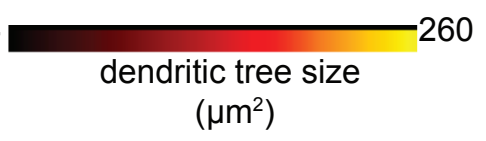

C)

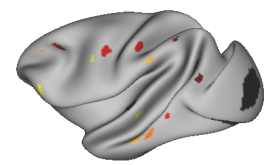

780

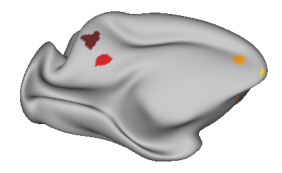

8337

dendritic spines per

layer 3 pyramidal cell
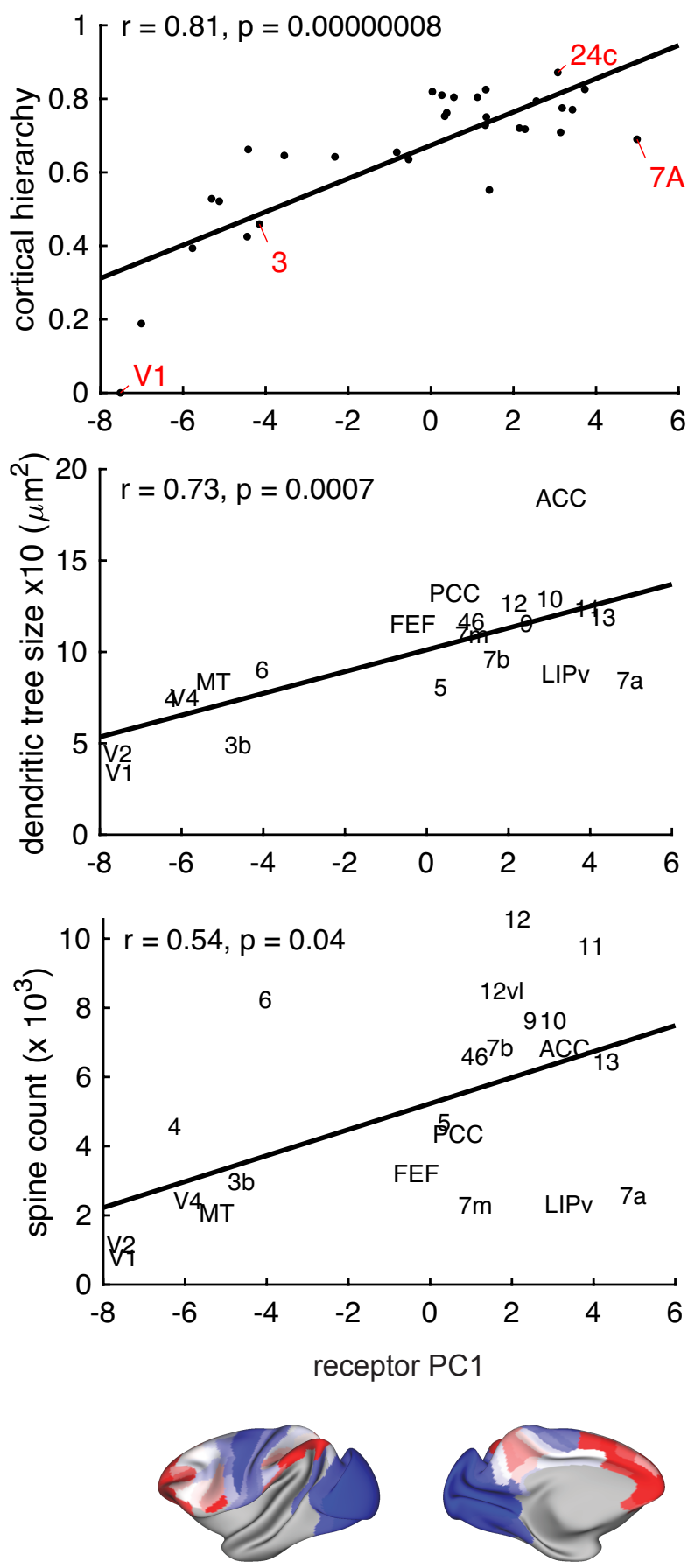

$-7.5 \square 2.5$

receptor $\mathrm{PC} 1$

Figure 3. The anatomical foundations of the principal receptor gradient. A) The cortical hierarchy was estimated based on laminar connectivity data. There was a strong positive correlation between the principal receptor gradient and the cortical hierarchy. $B$ and C) Dendritic tree size and spine count data were taken from a series of papers by Elston and colleagues (see text for references) and mapped to the common cortical space. Dendritic tree size and spines were both positively correlated with the principal receptor gradient. 


\section{Cortical areas and layers with high myelin content have low receptor density}

Myelin has an inhibitory effect on plasticity (McGee et al., 2005), and part of the role of myelin in development may be to stop the creation of unwanted connections (Braitenberg, 1962). The ratio of T1-weighted to T2-weighted signal is strongly correlated with levels of myelination in the cortical grey matter (Glasser and Essen, 2011). We found a strong negative correlation between $\mathrm{T} 1 \mathrm{w} / \mathrm{T} 2 \mathrm{w}$ ratio across the macaque cortex (obtained from Donahue et al., 2016) and the principal receptor gradient (Fig $4 \mathrm{~A}, r=-0.72, p=7 \times 10^{-19}$ ). This suggests that neurons in cortical areas with a high myelin content express less neurotransmitter receptors.

There is a lack of theoretical understanding of the relationship between the $\mathrm{T} 1 \mathrm{w} / \mathrm{T} 2 \mathrm{w}$ contrast and cortical myelin, which may break down under certain conditions, such as pathology (MacKay and Laule, 2016). To further probe the relationship between cortical myelin and receptor density, we compared the densities of all 14 receptors across cortical layers in V1 to the pattern of laminar myelination and cell density (Fig 4B). The cell density grey level index (GLI, which represents the volume fraction of cell bodies) was similar across all layers except for low densities in layers I and Vlb. Myelin was expressed most strongly in layers $\mathrm{IVb}$ and $\mathrm{VIb}$, and generally to a higher degree in infragranular than supragranular layers. Most receptors had highest densities in layers II and III, followed by layer $V$. Some receptors, including NMDA, GABA $A, G A B A_{B}, M_{2}$ and $5 \mathrm{HT}_{2}$ also had high densities in layer IVc. Most receptor densities were low in layers I, VI and IVb. Thus, the receptor density pattern is opposite to the myelin density pattern across layers in area $\mathrm{V} 1$, particularly when accounting for differences in GLI levels across layers. Thus the receptor gradient, and receptor expression more generally, may be constrained by cortical myelination. 
A)

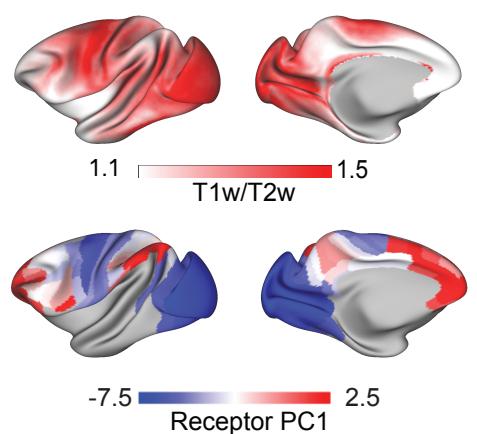

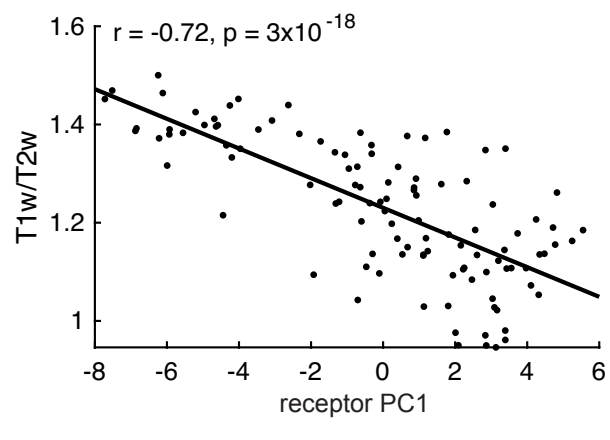

B)
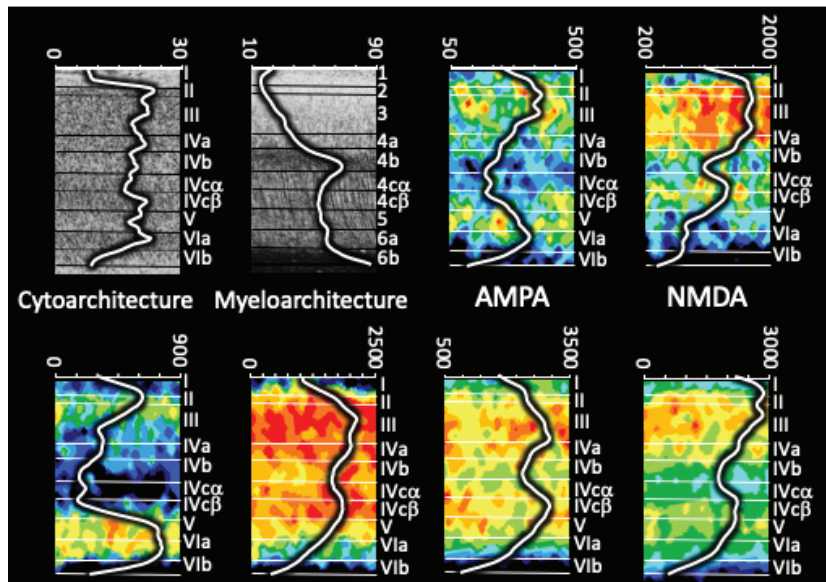

AMPA

NMDA

kainate
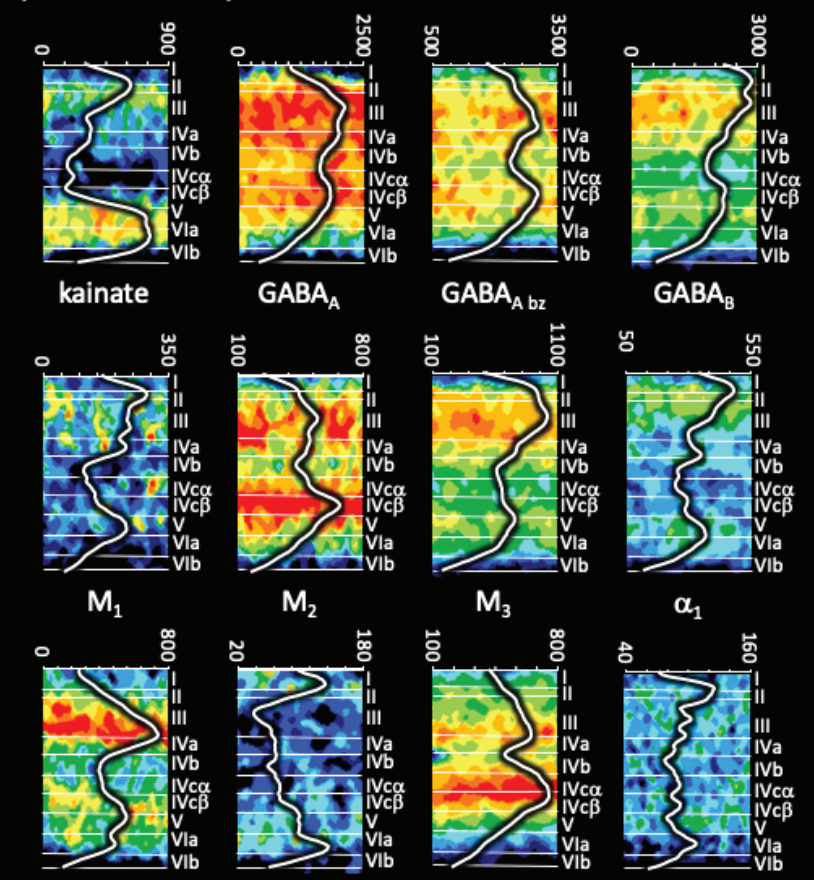

$\alpha_{1}$

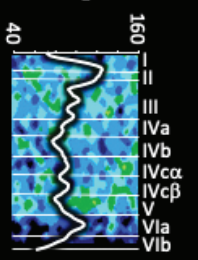

$\alpha_{2}$

$5-\mathrm{HT}_{1 \mathrm{~A}}$

$5-\mathrm{HT}_{2}$

$D_{1}$

low $\longleftarrow$ high

Figure 4. An inverse relationship between cortical myelin and receptor density. A) Cortical $T 1 w / T 2 w$ ratio, a proposed marker for myelin content, is strongly negatively correlated with the principal receptor gradient across 109 cortical areas. B) Receptor-, cyto-, and myeloarchitecture of the macaque primary visual cortex (V1). The Grey Level Index, which represents a measure of the volume fraction of cell bodies, myelin density and receptor concentration (in fmol/mg protein) throughout the cortical depth is provided by the profile curve overlaid onto each section. Note that the scale has been optimized for each profile to provide the best visualization of changes in receptor densities throughout the cortical ribbon. Roman and Arabic numerals indicate cyto- and myeloarchitectonic layers, respectively. Positions of cytoarchitectonic layers were transferred to the neighboring receptor images. 


\section{The principal receptor gradient is significantly correlated with the two principal functional connectivity gradients}

We next asked whether the principal receptor gradient may shape in-vivo interactions between cortical areas. A principal gradient of functional connectivity has previously been described in human cortex based on fMRI data (Margulies et al., 2016). Recently, Xu and colleagues identified shared gradients of functional connectivity across human and macaque cortex. This relied on quantifying the similarity of connectivity of each cortical point to each of 27 homologous cortical areas (Methods). We observed significant correlations between the principal receptor gradient and both the first (Fig $5 \mathrm{~A}, r=0.53, p=4 \times 10^{-9}$ ) and second (Fig $5 B, r=0.55, p=4 \times 10^{-10}$ ) functional connectivity gradients in macaque cortex. The two functional connectivity gradients appeared to reflect different aspects of the primary receptor gradient, with the first connectivity gradient ranging from early visual cortex to frontal and parietal areas, and the second ranging from primary somatosensory and motor areas to prefrontal cortex.

The shared functional connectivity gradients were used by $\mathrm{Xu}$ and colleagues to identify corresponding points in human and macaque cortex that best preserved global cortical connectivity patterns (Xu et al., 2020). This provided a crossspecies functional alignment, which was used to align the canonical seven cognitive networks of Yeo, Krienen and colleagues (Yeo et al., 2011) from the human cortex to the macaque cortex (Xu et al., 2020) (Fig 5C). We used this cross-species functional alignment to identify the receptor gradient expression across cognitive networks. The overlap of each area of the Julich Macaque Brain Atlas with the seven cognitive networks is quantified in Supplementary Table 1. We excluded the 'limbic' network due to the lack of vertices with receptor data, and focused on the remaining six networks. We found that the principal receptor gradient clearly separated the sensory (visual and somatomotor) networks, which had low receptor gradient scores, from the higher cognitive networks (dorsal attention, salience, frontoparietal and default mode), which had relatively higher gradient scores (Fig 5D-F). Almost all areas of the visual and somatosensory networks had negative gradient scores, while areas in the higher cognitive networks encompassed a range of positive and negative values (Fig 5D,E). Taken in conjunction with findings above, this suggests that higher cognitive networks contain neurons with a relatively high density of receptors, which may contribute to their flexibility of function. 
A)

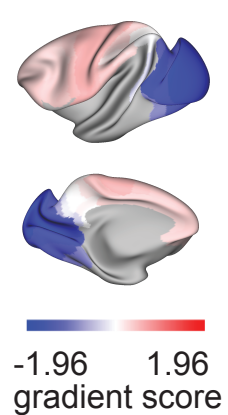

B)
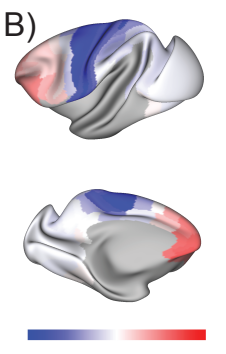

$-1.53 \quad 1.53$ gradient score

C)

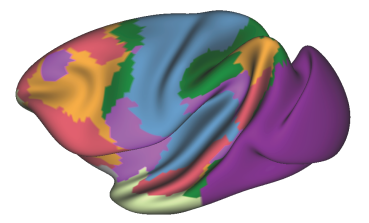

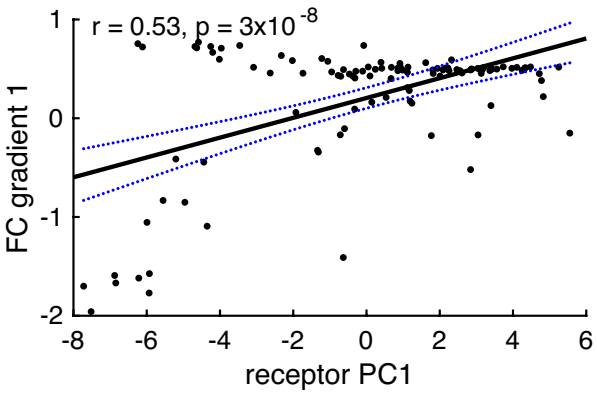
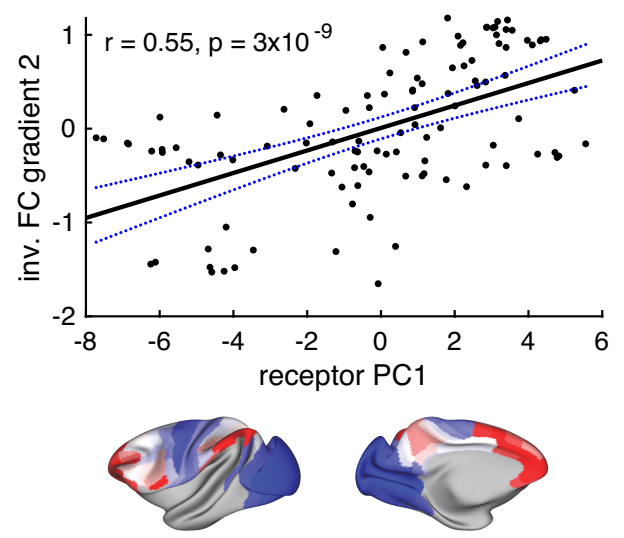

$-7.5$
D)

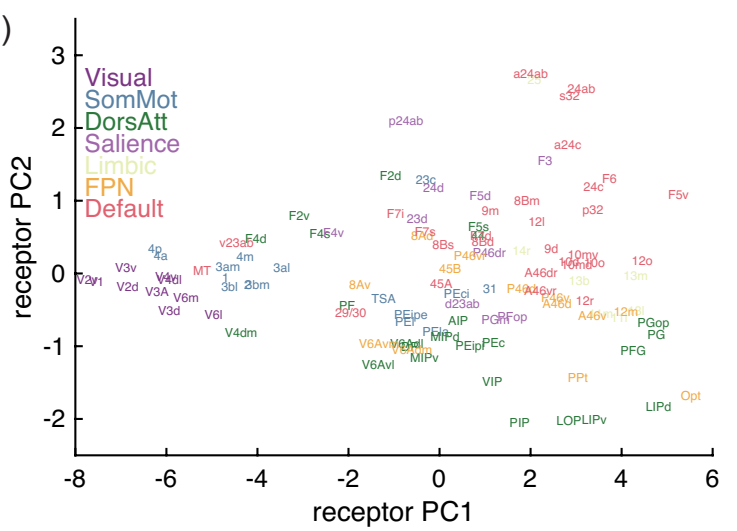

E)
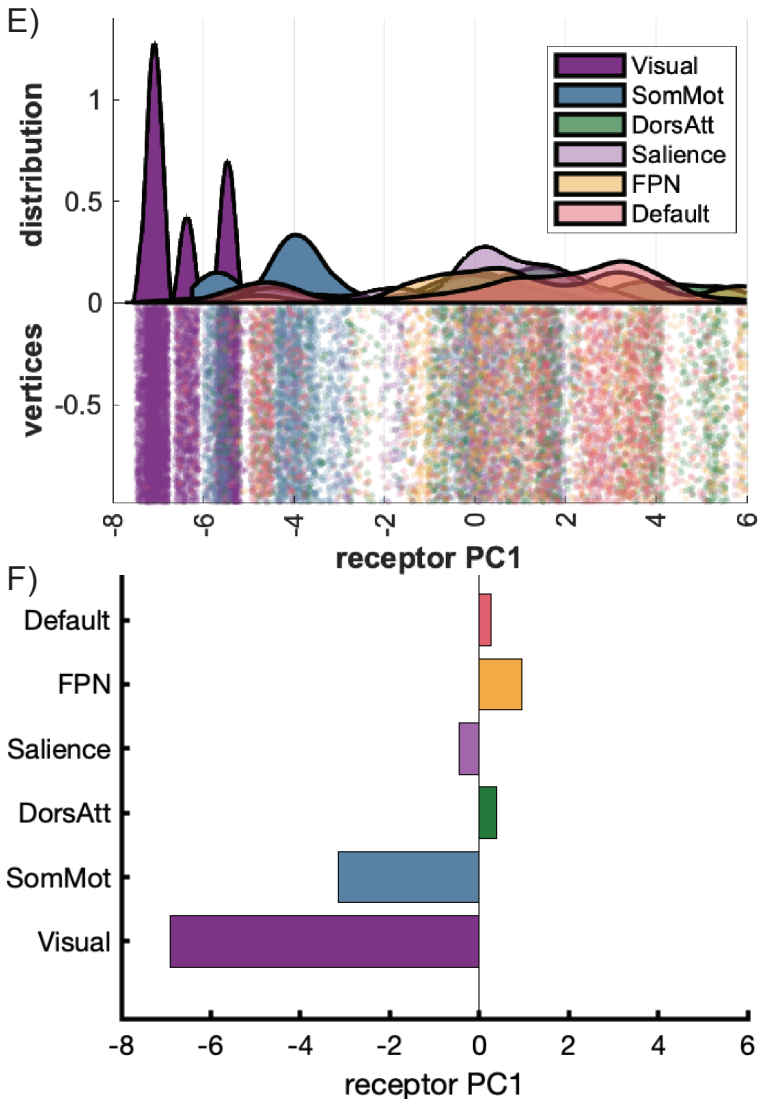

Figure 5. The principal receptor gradient underlies the principal gradients of in-vivo functional connectivity. $A$ and $B$ ) The first and second gradients of functional connectivity across macaque cortex were calculated in (Xu et al., 2020). Both gradients were significantly correlated with the principal receptor gradient. C) The canonical cognitive networks of Yeo, Krienen and colleagues (Yeo et al., 2011) mapped to the macaque cortex by Xu and colleagues using cross-species functional alignment (Xu et al., 2020). D) The cognitive networks mapped into receptor space. E) The distribution of receptor PC1 scores for vertices in each cognitive network shown on a raincloud plot (Allen et al., 2019). The 'limbic' network was excluded, due to a lack of receptor data. F) The mean principal component score of the principal receptor gradient within each cognitive network. 


\section{The secondary receptor gradient reflects variation in serotonin $5-H T_{1 A}$ receptors between higher order cortical areas}

The secondary receptor gradient separated higher order cortical areas (Fig 6A). Parietal areas such as LIPv lay at one end of the gradient, while cingulate areas such as $24 \mathrm{ab}$ and 25 lay at the other (Fig 6A). Visualization of the receptor fingerprints for representative areas revealed a striking difference in the serotonin $5-\mathrm{HT}_{1 \mathrm{~A}}$ receptor density, as well as differences in the $\mathrm{GABA}_{\mathrm{A}}$ density and AMPAkainate/NMDA ratio between areas at opposite ends of the secondary receptor gradient (Fig 6B). This was confirmed by correlations with secondary receptor gradient (Fig 6C) and with visualization of the coefficients of the secondary principal component (Fig S2). Areas at the top of the secondary receptor gradient, located in the subcallosal and anterior cingulate cortex, had a particularly high $5-\mathrm{HT}_{1 \mathrm{~A}}$ receptor density. There was no strong relationship between serotonin $5-\mathrm{HT}_{2}$ expression and the secondary receptor gradient (Supp. Fig. 3). The $5-\mathrm{HT}_{1 \mathrm{~A}}$ is the principal serotonin receptor that has a predominantly hyperpolarizing effect on neurons in the cortex (Celada et al., 2013).

Interestingly, major depressive disorder is associated with reduced serotonin signaling, and deep brain stimulation of the subcallosal white matter has been shown to be an effective treatment of depression in humans (Mayberg et al., 2005). Therefore, our finding provides a potential anatomical and molecular explanation for why selective serotonin reuptake inhibitors (SSRIs) reduce glucose metabolism in the subgenual cingulate in human patients with depression.

\section{The secondary receptor gradient separates the dorsal attention network from the default mode network and salience network}

We then investigated whether the secondary receptor gradient also corresponded to gradients of functional connectivity. Indeed, the secondary receptor gradient was significantly correlated with the third functional connectivity gradient (Fig 6D), with both gradients anchored in the lateral parietal cortex and precuneus. In contrast to the principal receptor gradient, which aligns with the cortical hierarchy, the secondary receptor gradient separates parietal and cingulate areas, which contribute to higher cognitive functions, and could thus facilitate switching between higher cognitive states in the brain.

We then analyzed the secondary receptor gradient score of each cognitive network (Fig 6E). There was a strong negative weighting in the dorsal attention network, and strong positive weighting in regions of the default mode network. These two higher cognitive networks typically are anticorrelated (Chai et al., 2012; Fox et al., 2005; Kelly et al., 2008; Yeo et al., 2015). Additionally, there was a strong positive loading in the salience network, which has been proposed to act as a 'switch' between default mode network activity and task-engaging frontoparietal network activity (Menon and Uddin, 2010). Thus, the secondary receptor gradient, and in particular the $5-\mathrm{HT}_{1 \mathrm{~A}}$ receptor expression pattern may capture a mechanism by which the cortex can switch between higher cognitive states dominated by the dorsal attention network or the default mode network. 
A)
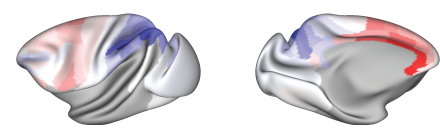

receptor PC2 score

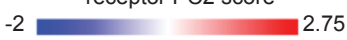

C)

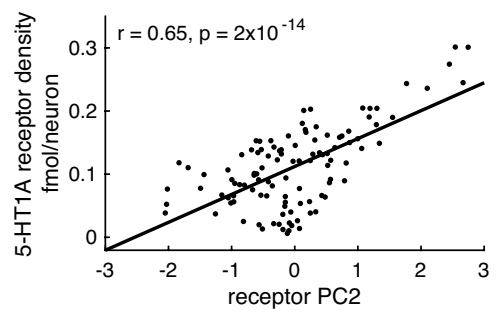

D)

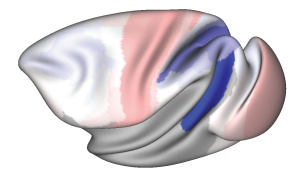

inv. gradient 3 score

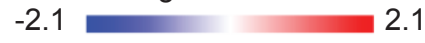

B)
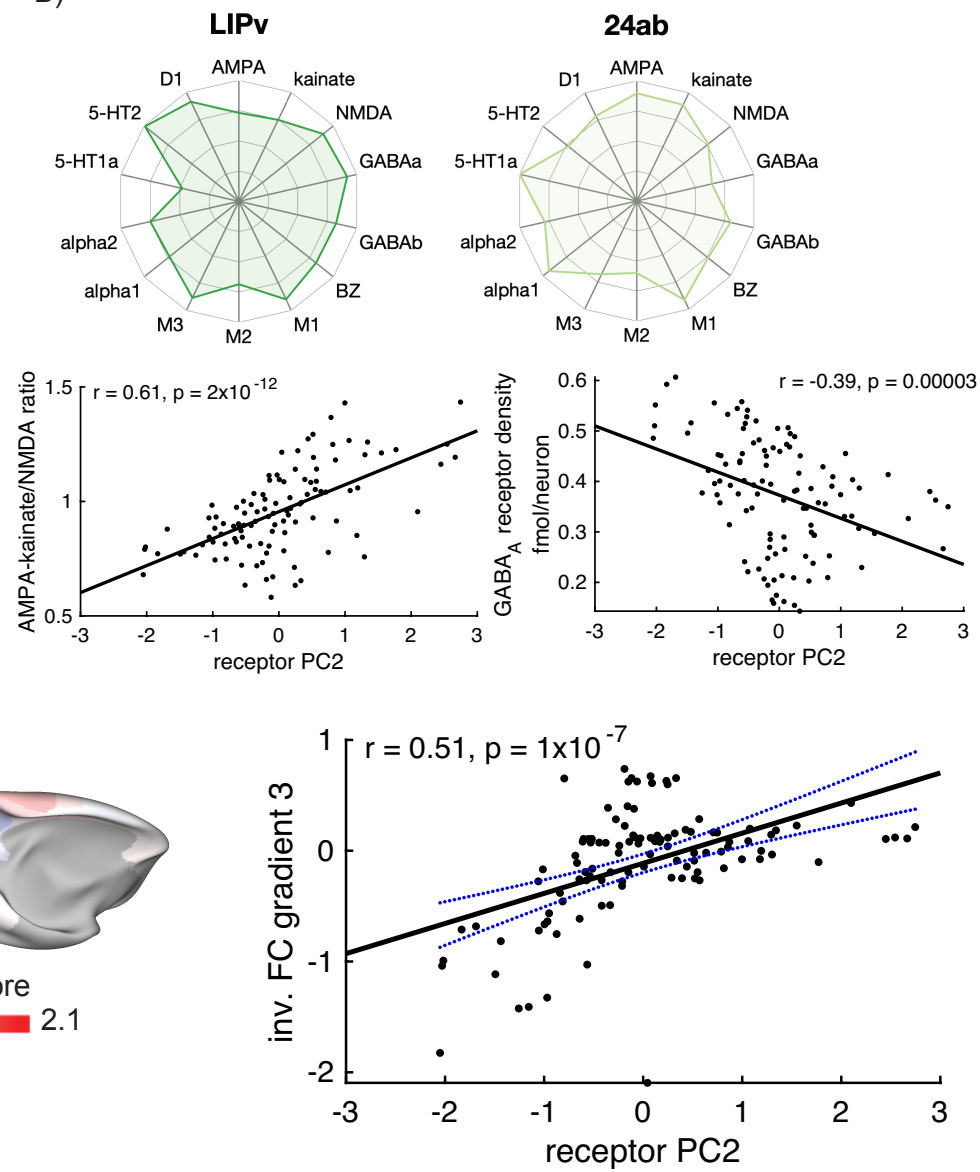

E)

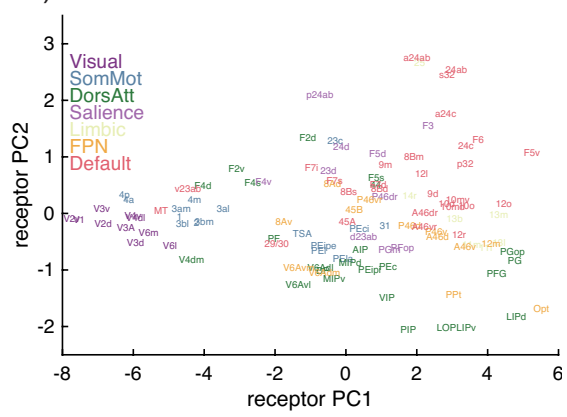

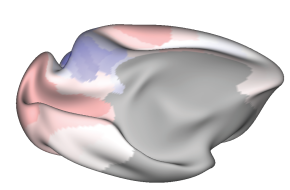

2.1
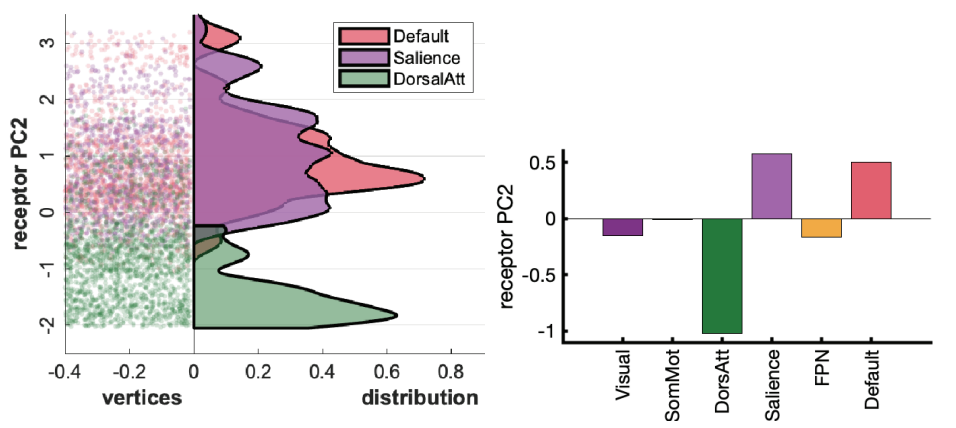

Figure 6. The secondary receptor gradient tracks differences in serotonin receptor densities between higher cognitive areas of cortex. A) Receptor PC2 (the secondary receptor gradient). B) Receptor fingerprints of areas 24ab and LIPV, which occupy opposing positions along the secondary gradient. The total receptor density per neuron is similar between the two areas, but there is an obvious difference in 5-HT $T_{1 A}$ receptor density per neuron. C) Receptor PC2 was positively correlated with $5-H T_{1 A}$ receptor density and the ratio of AMPA and kainate to NMDA receptors. Receptor $P C 2$ was also negatively correlated with the $G A B A_{A}$ receptor density. $D)$ Left. The third functional connectivity gradient. Right. The secondary receptor gradient was strongly correlated with the third functional connectivity gradient. E) The secondary receptor gradient separates the dorsal attention network from the default mode and salience networks. Left, cognitive networks in receptor space. Middle, distribution of receptor PC2 scores within the default mode, salience and dorsal attention networks. Right. Mean receptor PC2 scores for each cognitive network. 


\section{Macaque 5-HT $1 \mathrm{~A}$ receptor and human HTR1A gene expression peak in the default mode and salience networks}

We then investigated the correspondence between human HTR1A gene expression and macaque $5-\mathrm{HT}_{1 \mathrm{~A}}$ receptor expression. The HTR1A gene codes for the $5-\mathrm{HT}_{1 \mathrm{~A}}$ receptor. To do this we examined gene expression from the Allen Human Brain Atlas. This contains mRNA expression from hundreds of anatomical locations, with the left cortical hemisphere heavily sampled across 6 individual brains (Hawrylycz et al., 2012). We mapped gene expression onto a comprehensive 180 area multimodal parcellation of the human cortex (Glasser et al., 2016). HTR1A gene expression peaked in anterior/medial temporal cortex, insula, subcallosal/anterior cingulate and areas of postero-medial cortex (posterior cingulate/precuneus) (Fig 7A). We reverse-translated this map to the macaque cortex using cross-species functional alignment (Xu et al., 2020) (Fig $7 \mathrm{~A}$, Methods). There was a strong positive correlation between human HTR1A gene and macaque 5-HT 1 A receptor expression $\left(r=0.66, p=6 \times 10^{-15}\right.$, Fig 7B). Both human HTR1A gene and macaque $5-\mathrm{HT}_{1 \mathrm{~A}}$ receptors were expressed similarly across cognitive networks, with the order of gene/receptor expression preserved (from lowest to highest expression: visual, somatomotor, dorsal attention, frontoparietal, default, salience; Fig 7C,D). Note that this expression is largely captured by the first two receptor gradients. The low expression in visual and somatomotor networks is captured by the principal receptor gradient. The ordering of the higher cognitive networks is captures by the secondary receptor gradient.

\section{5-HT $T_{1 A}$ receptor expression across cortex is largely conserved across species}

We then assessed the pattern of 5- $\mathrm{HT}_{1 \mathrm{~A}}$ receptor expression across cortex in the human, macaque and rat using in-vitro receptor autoradiography (Fig 7E). In the human, 5- $\mathrm{HT}_{1 \mathrm{~A}}$ receptor expression peaked in area 25 (subcallosal cingulate), with high density in other anterior cingulate and frontal regions and low density in motor and visual cortex. This general pattern was also true in macaque and rat cortex. However, the peak of $5-\mathrm{HT}_{1 \mathrm{~A}}$ receptor density appears to shift slightly from area 25 to neighboring parts of anterior cingulate in the macaque, with a similar shift even more apparent in the rat. In the rat, the gradient of $5-\mathrm{HT}_{1 \mathrm{~A}}$ receptor density across cortex was generally similar to that seen in the macaque and human, but was somewhat flatter. 
A)

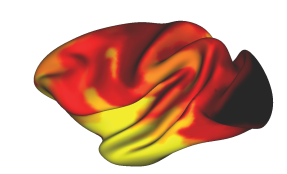

HTR1A mRNA

on macaque cortex

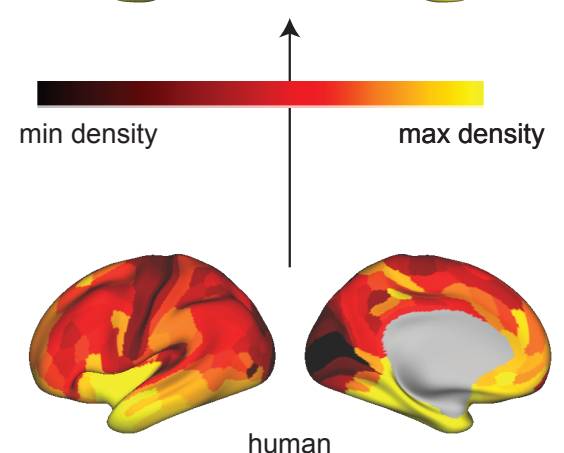

HTR1A mRNA

C)

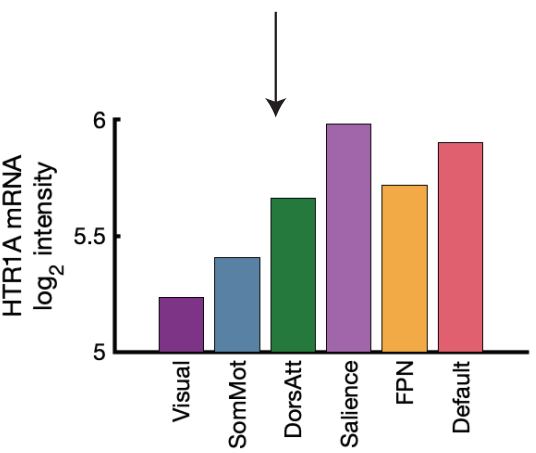

B)

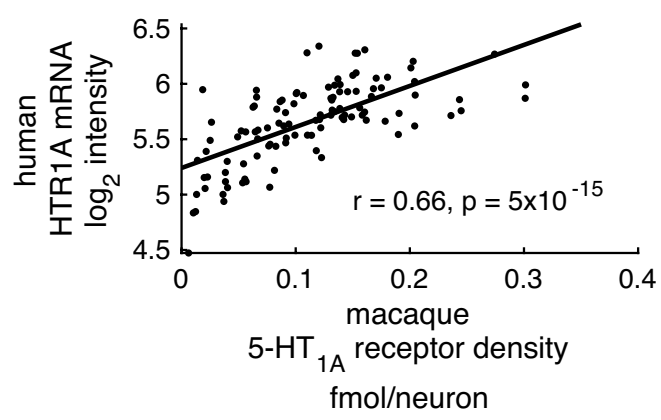

D)

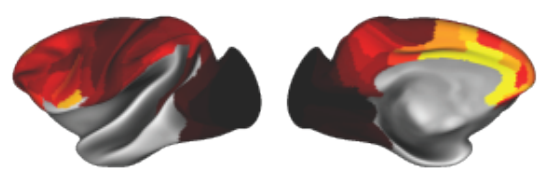

macaque

5- $\mathrm{HT}_{1 \mathrm{~A}}$ receptor density

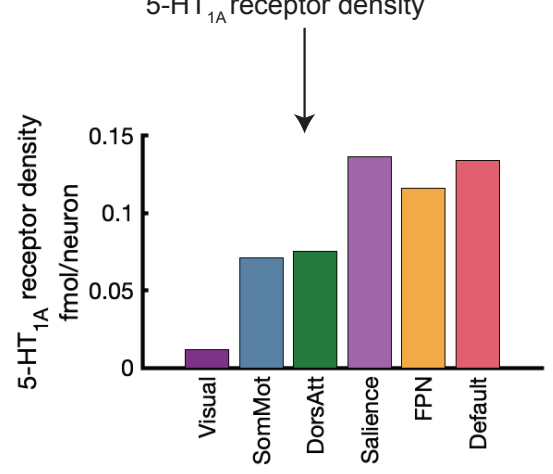

E)

human

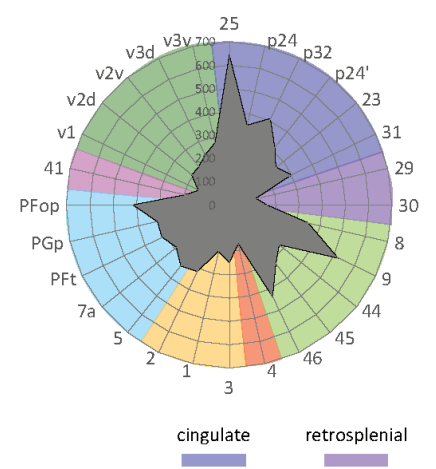

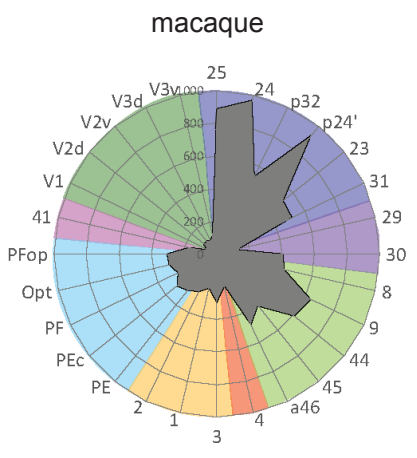

frontal motor

somatosensory parietal

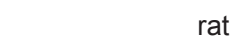

rat

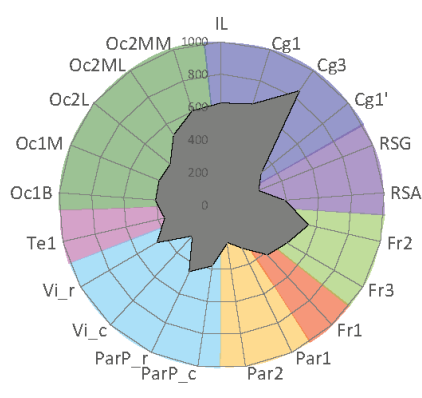

auditory occipital

Figure 7. Serotonin 5-HT $1 \mathrm{~A}$ receptor expression across the human, macaque and rat cortex. A) We mapped human HTR1A gene expression data (Hawrylycz et al., 2012) to the human cortex and then to the macaque cortex using cross-species functional alignment. B) Human gene expression and macaque receptor expression for the 5-HT $T_{1 A}$ receptor were positively correlated. $C$ and D) Human HTR1A gene expression and macaque 5-HT $T_{1 A}$ receptor expression are expressed similarly across cognitive networks, peaking in the Default Mode and Salience networks. E) The density of 5-HT ${ }_{1 A}$ receptors (in fmol/mg protein) across multiple areas of human, macaque and rat cortex. 5-HT $1 \mathrm{~A}$ receptor density is high in subcallosal or anterior cingulate in all species, although the area with peak density shifts slightly across species. 


\section{Discussion}

In this work, we measured expression of 14 receptor types per neuron across 109 regions of macaque cortex, and described their general organizational principles. We discovered a principal gradient of cortical receptor expression along the cortical hierarchy that accounted for about $80 \%$ of variance in the entire receptor dataset. This 'principal receptor gradient' tracked the increased expression of all receptor types from early sensory cortex to regions of cortex contributing to higher cognitive processes. We identified a plausible neural architecture to house this increased receptor density. Brain regions with more receptors per neuron contained pyramidal cells with larger dendritic trees, more dendritic spines, and displayed a lower T1w/T2w ratio in MRI scans, indicative of reduced grey matter myelin. The inverse relationship between receptor density and myelin was confirmed across layers in $\mathrm{V} 1$. The patterns of receptor expression were strongly correlated with in-vivo gradients of functional connectivity, suggesting a neurochemical basis for large-scale cortical connectivity patterns. The secondary receptor gradient was largely driven by expression of the serotonin 5- $\mathrm{HT}_{1 \mathrm{~A}}$ receptor. The pattern of macaque $5-\mathrm{HT}_{1 \mathrm{~A}}$ receptor expression across cortex was very similar to human $5 \mathrm{HT}_{1 \mathrm{~A}}$ receptor and gene expression, and to a lesser degree to rat $5 \mathrm{HT}_{1 \mathrm{~A}}$ receptor expression. The second gradient segregated the dorsal attention from the default mode network and salience network. This suggests the possibility of a serotonergic basis for a switch between external and internal modes of attention.

In recent years, the description of cortical organization in terms of gradients of gradually changing properties (Braitenberg, 1962; Sanides, 1962) has returned to fashion (Wang, 2020). Gradients of connectivity (Margulies et al., 2016; Xu et al., 2020), cell-type densities (Kim et al., 2017), receptor expression (Goulas et al., 2021) and gene expression (Burt et al., 2018; Fulcher et al., 2019) have been described. Many of these properties vary along an axis that aligns with the cortical hierarchy, which can be estimated based on patterns of laminar connectivity (Felleman and Van Essen, 1991; Froudist-Walsh et al., 2020; Markov et al., 2014b; Theodoni et al., 2020). One of the mysteries of such organization is how gradual changes in anatomical properties can lead to the emergence of strikingly different functions. Here we described a principal receptor gradient in macaque cortex that increased along the hierarchy. Along the principal receptor gradient, we show that neurons that are further up the hierarchy express on average 4 times higher densities of neurotransmitter receptors than neurons at the lowest end of the hierarchy. This includes not only the ubiquitous excitatory glutamate and inhibitory GABA receptors, but also 8 types of neuromodulatory receptors. We found that neurons with more receptors also contain much larger dendritic trees and more spines, are thus anatomically equipped to integrate information from a larger number of sources. This coincides with the increased neuronal timescales with which neurons in higher areas integrate information (Chaudhuri et al., 2015; Gao et al., 2020; Hasson et 
al., 2008; Murray et al., 2014; Raut et al., 2020). This extra receptor capacity may endow neurons in higher cortical areas with the ability to respond flexibly when faced with changing demands. In contrast, the receptor-light neurons of early sensory cortex may receive relatively little modulation, which may ensure that sensory stimuli are processed reliably in different contexts.

The second receptor gradient was dominated by serotonin $5-\mathrm{HT}_{1 \mathrm{~A}}$ receptor expression. This peaked in the cingulate cortex, with high expression in the subcallosal cingulate, which is a principal target of deep brain stimulation for treating depression. The extremely high expression of $5-\mathrm{HT}_{1 \mathrm{~A}}$ receptors in this same brain regions provides a plausible explanation for why deep brain stimulation of the subcallosal cingulate and selective serotonin reuptake inhibitors (SSRIs) have almost identical effects on cerebral blood flow (Mayberg et al., 2005, 2000). SSRIs increase the activation of 5- $\mathrm{HT}_{1 \mathrm{~A}}$ receptors, which are most prominently expressed in subcallosal and anterior cingulate (Fig 7), where they act to reduce neural activity and counteract the increased glucose metabolism seen in patients with depression in this area (Mayberg, 2003, 1997). Although gene expression is not always a good predictor of receptor expression (Arnatkeviciute et al., 2019; Schwanhäusser et al., 2011), a previous study using $\mathrm{PET}$ found that gene and receptor expression are closely aligned for the 5- $\mathrm{HT}_{1 \mathrm{~A}}$ receptor in humans (Beliveau et al., 2017). Here, using exquisite resolution of invitro autoradiography, we found that $5-\mathrm{HT}_{1 \mathrm{~A}}$ receptor density in the macaque was very similar to the HTR1A gene expression and receptor expression in humans (Fig 7). The pattern of 5- $\mathrm{HT}_{1 \mathrm{~A}}$ receptor expression in the rat also peaked in the cingulate cortex, however the gradient of expression was flatter in the rat than in the macaque or human brain. Notably, the laminar receptor expression pattern in the rat differs considerably from that observed in human or macaque cortex (Zilles and Palomero-Gallagher, 2017a), and serotonin receptors are expressed on different cell types between the mouse and human (Hodge et al., 2019). The differences between the primate and rodent receptor expression across brain areas, layers and cell types suggest caution when designing and interpreting rodent models of depression. In contrast, the closely overlapping serotonin receptor anatomy between macaque monkey and human reported here, suggests that, the macaque may be a promising animal model for depression.

In contrast to the principal receptor gradient, which separates early sensory from higher cognitive areas, the second receptor gradient segregated higher cognitive networks. In particular, the second gradient separated the dorsal attention network from the default mode network and salience network. Association cortex is often divided into four distributed cognitive networks (dorsal attention, salience, frontoparietal, default), with a fifth higher cognitive network, the 'limbic network' often included within the default network (Uddin et al., 2019). These networks each occupy parts of the frontal, parietal and temporal lobes, and in several patches of cortex appear in a consistent order along the cortical surface (Margulies et al., 2016). The dorsal attention network usually lies closest to sensory areas, and is highly active when attention must be focused on external 
stimuli (Corbetta and Shulman, 2002). The default mode network lies furthest away from sensory areas, and is deactivated during similar tasks, but highly active during tasks that require a disconnection of attention from the external world, such as autobiographical memory, or imagination (Andrews-Hanna et al., 2014; Buckner et al., 2008; Raichle, 2015; Shulman et al., 1997; Spreng and Grady, 2009). Activity in these two networks is often anticorrelated (Chai et al., 2012; Fox et al., 2005; Kelly et al., 2008; Yeo et al., 2015), in line with their opposing roles in cognition. The frontoparietal network (known by several other names, including the multiple demand system, the cognitive control network and the central executive network (Uddin et al., 2019)), lies between these two networks and may dynamically couple with either, depending on task demands (Dixon et al., 2018; Spreng et al., 2010). In line with this intermediate role, the frontoparietal network lay between the dorsal attention and default mode networks along the secondary receptor gradient.

Previous models have suggested that the antagonism between the dorsal attention network and the default mode network may result from direct longrange excitatory connections that target inhibitory neurons in the opposing network (Anticevic et al., 2012). We propose that the cognitive networks may represent distinct attractor states of the large-scale system, which can be seen as relatively stable patterns of spatiotemporal activity. Based on our findings, release of serotonin would engage inhibitory $5-\mathrm{HT}_{1 \mathrm{~A}}$ receptors principally in the default-mode network, and the salience network. Previous evidence suggests that the salience network acts as a switch from the default mode network to frontoparietal networks focused on external attention (Menon, 2011; Menon and Uddin, 2010). Serotonin neuron activity closely resembles a "surprise" signal (Matias et al., 2017), and surprising stimuli activate the salience network (Menon, 2015), which may engage the dorsal attention network to focus attention externally towards such stimuli. The distribution of $5-\mathrm{HT}_{1 \mathrm{~A}}$ receptors on excitatory and inhibitory cell types (Puig et al., 2010; Puig and Gulledge, 2011; Xiang and Prince, 2003) in the default mode and salience networks may determine whether serotonin release has a similar effect on both networks. The $5-\mathrm{HT}_{1 \mathrm{~A}}$ receptor is thought to dominate cortical serotonin processing under normal conditions, due to its high affinity for serotonin compared to $5-\mathrm{HT}_{2}$ receptors (Hoyer et al., 1986a, $1986 \mathrm{~b}, 1985)$. In contrast, the $5-\mathrm{HT}_{2}$ system is engaged by massive serotonin release under extreme conditions (Carhart-Harris and Nutt, 2017), when attention needs to be rapidly shifted to external events. Accordingly, the excitatory effects of the $5-\mathrm{HT}_{2}$ receptors may complement the $5-\mathrm{HT}_{1 \mathrm{~A}}$ effects by preferentially exciting the dorsal attention and frontoparietal networks (Fig S3). This is compatible with recent findings that genes for neuromodulatory receptors are expressed at cortical locations that may affect the flow of brain states over time (Shine et al., 2019), and suggests a specific mechanism for shifting activity between cardinal cognitive networks.

The receptor architecture of human cortex has recently been described (Zilles and Palomero-Gallagher, 2017b), with dimensionality-reduction techniques 
finding a gradient comparable to the principal receptor gradient we present here (Goulas et al., 2021; Zilles and Palomero-Gallagher, 2017b). However, there are a few key differences with the present study. First, we study macaque cortex, which allows for comparison with gold-standard invasive anatomy, imaging and physiology data. Second, analyzing the macaque cortex allowed us to combine receptor autoradiography data with neuron density across cortex (Collins et al., 2010). This enabled us to estimate the density of 14 types of receptor per neuron, which is important to understand the functional significance of changes in receptor densities. One clear result that emerges from processing the data in this manner is that several receptors that have high density (in the raw data) in V1 do so principally because of the remarkably high neuron density in that area. Third, we were able to bring multiple invasive anatomical and in-vivo functional datasets into a common space, which enabled us to identify the anatomical structure underpinning the receptor gradients, as well as discover the potential significance of such gradients in guiding functional communication in the cortex.

Recent developments in large-scale recording techniques have highlighted the distributed nature of cognitive functions. Despite these advances, our theoretical understanding of how distinct cognitive functions emerge across different areas of the cortex is limited. The large-scale receptor data presented here can provide an anatomical basis for future large-scale models of neuromodulation of brain connectivity (Deco et al., 2018), activity and cognitive function (Cano-Colino et al., 2014; Froudist-Walsh et al., 2020) and for understanding the emergence of flexible higher cognition along the cortical hierarchy.

\section{Methods:}

\section{In-Vitro Receptor Autoradiography of the Macaque Cortex}

We analysed the brains of three adult male Macaca fascicularis specimens (between 6 and 8 years old; body weight between 5.2 and $6.6 \mathrm{~kg}$ ) obtained from Covance Preclinical Services $\mathrm{GmbH}$, Münster, where they were used as control animals for pharmaceutical studies performed in compliance with legal requirements. All experimental protocols were in accordance with the guidelines of the European laws for the care and use of animals for scientific purposes.

Animals were sacrificed by means of an intravenous lethal dose of sodium pentobarbital. Brains were removed immediately from the skull, and brain stem and cerebellum were dissected off in close proximity to the cerebral peduncles. Hemispheres were separated and then cut into a rostral and a caudal block by a cut in the coronal plane of sectioning within the central sulcus. These blocks were frozen in isopentane at $-40^{\circ} \mathrm{C}$ to $-50^{\circ} \mathrm{C}$, and then stored in airtight plastic bags at $-70^{\circ} \mathrm{C}$. Each block was serially sectioned in the coronal plane (section thickness $20 \mu \mathrm{m}$ ) using a cryostat microtome (CM 3050, Leica, Germany). Sections were thaw-mounted on gelatine-coated slides, freeze-dried overnight 
and processed for visualization of receptors, cell bodies (Merker, 1983) or myelin (Gallyas, 1979).

Quantitative in vitro receptor autoradiography was applied to label 14 receptors from different neurotransmitter systems according to previously published protocols (Palomero-Gallagher and Zilles, 2018b; Zilles et al., 2002b; Supplementary Table 1), and encompassing a preincubation to rehydrate sections, a main incubation with a tritiated ligand in the presence of or without a non-labeled displacer, and a final rinsing step to terminate binding. Incubation with the displacer enabled to determine the proportion of displaceable, nonspecific binding, which was less than $5 \%$ of the total binding. Thus, total binding is considered to be equivalent of specific binding. Sections were dried in a cold stream of air, exposed together with plastic scales of known radioactivity against tritium-sensitive films (Hyperfilm, Amersham) for 4-18 weeks depending on the receptor type.

Ensuing autoradiographs were processed by densitometry with a videobased image analysing technique (Palomero-Gallagher and Zilles, 2018b; Zilles et al., 2002b). For details of the method, please see (Palomero-Gallagher and Zilles, 2018b; Zilles et al., 2002b). The mean receptor density for each area was determined by density profiles extracted vertical to the cortical surface over a series of 3-5 sections per receptor type and animal using Matlab-based in house software (Palomero-Gallagher and Zilles, 2018b). Identification of cortical areas and layers was carried out by comparison with the adjacent cell-body stained histological sections. Finally, autoradiographs were pseudo-colour coded by linear contrast enhancement and assignment of equally spaced density ranges to a spectral arrangement of eleven colours for visualization purposes.

Creation of surface representation of cyto- and receptor-architectonic atlas and receptor data.

One-hundred-and-nine cortical areas were defined based on their receptor- and cyto-architecture, as described in (Impieri et al., 2019; Niu et al., 2021, 2020; Rapan et al., 2020) and upcoming publications on the prefrontal cortex, cingulate and occipital lobe. We call this parcellation the Julich Macaque Brain Atlas. The location and extent of the cortical areas were delineated in the 3D space of the Yerkes19 surface (Donahue et al., 2016) by LR, MN and NPG using the connectome workbench software (https://www.humanconnectome.org/software/connectome-workbench) by carefully aligning boundaries to macroanatomical landmarks identified using the cytoarchitecture. The location of all regions on the Yerkes19 surface were independently checked and verified by MN, SFW, LR and NPG. 3D reconstruction of the hemisphere was obtained using the Connectome Workbench software. Additionally, the mean receptor densities of all 14 receptor types have been projected onto the corresponding area on the Yerkes 19 surface for visualization.

Creation of surface representation of regions for neural density data. 
Collins and colleagues measured the neural density across the macaque cortex (Collins et al., 2010) using the isotropic fractionator method (Herculano-Houzel and Lent, 2005). In that paper, the cortex is presented as a flat-map divided into sections in their Figure 2 and S3. We used these maps, along with several sulcal, gyral and areal landmarks provided in their Figure 2 to estimate the location of each cortical section (i.e. the Vanderbilt sections) on the Yerkes 19 surface. This was performed by SFW and independently verified by LR, MN and NPG. This allowed us to estimate the neural density in each of the 109 areas of the Julich Macaque Brain Atlas. For each area in the Julich Macaque Brain Atlas, we took a weighted average of the neural density in each of the overlapping Vanderbilt sections, weighted by the number of vertices of overlap. The neuron density data was originally in units of neurons per gram, and the receptor density data in $\mathrm{fmol} / \mathrm{mg}$ protein. To estimate the receptor density in fmol per neuron, we used the previously reported figure that $8 \%$ of brain tissue is protein (Mcllwain and Bachelard, 1972). This amounts to multiplying by a constant, and does not affect the calculation of the gradients via principal components analysis or the correlations with other maps.

\section{Receptor gradients}

To identify the receptor gradients, we z-scored the receptors-per-neuron data and performed a principal components analysis. Z-scoring ensured that high density receptors would not dominate the principal components.

\section{Cortical hierarchy and retrograde tracing data}

The cortical connectivity data were obtained from Henry Kennedy (Lyon, France) and are available at core-nets.org. The retrograde tracing data was obtained following injections into 40 cortical regions using consistent methods in the same laboratory. This ensures high quality and consistency of weighted and directed connectivity data (Kennedy et al., 2013). This database is regularly updated with new connectivity data (Markov et al., 2014a). We recently estimated the cortical hierarchy using this data, based on the laminar patterns of connections (FroudistWalsh et al., 2020). For details of the method, please see (Froudist-Walsh et al., 2020; Markov et al., 2014b). The parcellation for this connectivity data (the Lyon Macaque Brain Atlas; known in BALSA as the M132 atlas) has previously been made available on the Yerkes 19 surface (Donahue et al., 2016). We used this to fill in hierarchy values on the surface. We then estimated the receptor gradient values within each area of the Lyon Macaque Brain Atlas, weighted by the extent of overlap with each area of the Julich Macaque Brain Atlas.

Creation of surface representation of dendritic data. 
Elston and colleagues measured the dendritic tree length and spine density of layer III pyramidal neurons in a series of studies. In order to compare this data with the receptor data, we first mapped the injected regions as described by Elston and colleagues onto the Yerkes19 template. Borders for injection sites in the series of papers by Elston and colleagues were drawn on the Yerkes19 template by SFW. Direct comparison with the hand-drawn maps was possible for areas V1, V2, MT, LIPv, 7a, V4, TEO, STP, IT, Ant. Cing., Post. Cing, TEpd, 12vl, A1, 3b, 4, 5, 6, 7b, 9, 13, 46, 7m (Elston, 2001; Elston et al., 2011a, 2010, 2009, 2005, 1999; Elston and Rockland, 2002; Elston and Rosa, 1998a, 1997). Direct comparison with the anatomical drawings was supplemented by additionally comparing the drawn locations with the anatomical references cited therein, and, where possible, atlases available within connectome workbench that were cited in the studies by Elston. Areas 10, 11 and 12 (Elston, 2000) were described with reference to (Preuss and Goldman-Rakic, 1991). The injection in area TEa, as described in (Elston et al., 2001) used the maps in (Seltzer and Pandya, 1978) for area definition. We used these maps to approximate the injection location. Area STP, injected in (Elston, 2001; Elston et al., 1999) was identified with the corresponding region STPp in the atlas of Felleman and Van Essen (Felleman and Van Essen, 1991). Area FEF was identified according to the description in (Elston and Rosa, 1998b), lying on the anterior bank of the medial aspect of the arcuate sulcus. All identified injection sites on the cortical surface were independently verified by MN, LR and NPG. The receptor principal component score was averaged within all vertices in each injection site in order to compare dendritic and receptor data.

\section{Cortical T1w/T2w data}

The T1w/T2w data was acquired by (Donahue et al., 2016), and was downloaded from the BALSA neuroimaging website (Van Essen et al., 2017). To compare the $\mathrm{T} 1 \mathrm{w} / \mathrm{T} 2 \mathrm{w}$ data with the receptor data, we simply averaged the T1w/T2w signal within each of the 109 areas of the Julich Macaque Brain Atlas.

\section{Functional connectivity data}

$\mathrm{Xu}$ and colleagues recently identified matching functional connectivity gradients in human and macaque cortex (Xu et al., 2020). These matched gradients were used to develop a mapping between human and macaque cortex that best aligns points (vertices) in macaque and human cortex according to their global functional connectivity patterns (Xu et al., 2020). Here we used the human-tomacaque mapping developed in that manuscript. We provide some details of how that mapping was calculated.

Resting-state fMRI data from 19 macaque monkeys was collected with no contrast agent in Oxford (Noonan et al., 2014). These data were downloaded 
from the PRIME-DE database (Milham et al., 2018) and pre-processed using a Human Connectome Project-like pipeline (Xu et al., 2015, 2019, 2018). Similarly, minimally preprocessed human resting-state fMRI data from the Human Connectome Project was used (Glasser et al., 2013).

Gradients of functional connectivity were defined using the diffusion map method (Coifman and Lafon, 2006; Margulies et al., 2016). Diffusion maps rely on a measure of similarity between each cortical point. In previous studies, the similarity of functional connectivity patterns between cortical vertices was used to define the similarity matrix (Margulies et al., 2016). To compare macaque and human cortex, a cross-species joint-similarity matrix had to be used as input to the diffusion mapping.

The diagonal blocks of the joint-similarity matrix (corresponding to similarity of human to human cortical vertices, and monkey to monkey cortical vertices) were based on (cosine) similarity of functional connectivity patterns, as in previous studies (Margulies et al., 2016). To create a similarity measure between each point on the macaque cortex and each point on the human cortex, 27 landmark regions were used (related to the approach by (Mars et al., 2018)). These had previously been identified as homologous regions between human and macaque monkeys (Mars et al., 2011; Neubert et al., 2014; Sallet et al., 2013; Van Essen and Dierker, 2007). For each species, the similarity between the functional connectivity patterns of each vertex and each landmark were calculated (for a similar approach, see (Mars et al., 2018)). Then the human vertex to monkey vertex similarity could be calculated by assessing how their connectivity resembled that of the 27 landmark regions. The matrix containing this (cosine) similarity for each pair of human and monkey vertices, and its transpose, made up the off-diagonal squares of the joint-similarity matrix.

This cross-species joint-similarity matrix was used as input to the diffusion map. This produced shared cross-species gradients of functional connectivity. To create the point-to-point cross-species mapping, these functional connectivity gradients were used as input to multimodal surface matching (MSM) (Robinson et al., 2014), the method recently used to define a high-quality parcellation of human cortex based on multimodal imaging features (Glasser et al., 2016). Once this mapping is established, it can be used to transfer maps or parcellations across species. Xu et al demonstrated the accuracy of this method through accurate alignment of myelin maps across species. However, even for bestmatching homologous points of cortex, there are cross-species differences in functional connectivity patterns. These cross-species functional connectivity differences are greater for associative than sensory regions of cortex (Xu et al., 2020).

The definition of seven cognitive networks in human cortex by Yeo, Krienen and colleagues has become a standard network definition in the field (Yeo et al., 2011). Some authors have since suggested that the limbic network in fact forms 
part of the default mode network, leaving six canonical cognitive networks (Uddin et al., 2019). Xu et al transferred the cognitive networks defined in (Yeo et al., 2011) from human to macaque using this cross-species functional alignment $(\mathrm{Xu}$ et al., 2020). We used this human-to-monkey mapping to identify the receptor expression across cognitive networks. Due sparse receptor mapping in the limbic network, we excluded this cognitive network from analysis.

\section{Human gene expression data}

Human gene expression data was downloaded from the Allen Human Brain Atlas (Hawrylycz et al., 2012). We analyzed data from hundreds of microarray samples across the left cortical hemispheres of six donors (5 male, 1 female). We replicated the methods in (Burt et al., 2018) using in-house code in Matlab (github.com/seanfw/genemapper), with the following exceptions: 1) Instead of using the $\mathrm{MNI}$ coordinates supplied by the Allen Institute, we used the nativespace sample coordinates, and performed a surface registration of the individual brains to the HCP group average surface. Surface registration is well suited to detect the sulcal patterns of postmortem brains, and relatively unaffected by nonlinear deformations to subcortical structures and white matter (such as squishing) that can affect postmortem brains. 2) Rather than mapping genes to brain areas for each subject and then averaging across subjects, we mapped genes to brain areas for all subjects together. This reduces the need to interpolate values for brain areas that contain no samples, but may be more vulnerable to individual differences in gene expression. Similar to (Arnatkeviciute et al., 2019), we found that the spatial patterns of gene expression were similar regardless of whether the gene expression data were normalized by z-scoring across samples or across genes. We extracted the HTR1A gene expression pattern, and mapped this to the macaque cortex using the cross-species functional alignment detailed above (Xu et al., 2020).

\section{Statistical analysis}

Following mapping of all data to a common space, Pearson correlations were performed between the receptor principal components and each of the other data-types mentioned above. P-values were Bonferroni corrected based on the number of correlations between receptor gradients and structural or functional maps.

\section{Acknowledgments}

This project was funded by (NIH/BMBF) CRCNS grant (nos. R01MH122024 and 01GQ1902) to NPG and XJW; NIH grant R01MH062349, ONR grant N00014 and James Simons foundation grant 543057SPI to XJW and the European Union's Horizon 2020 Framework Programme for Research and Innovation under the Specific Grant Agreements 785907 (Human Brain Project SGA2) and 945539 (Human Brain Project SGA3) to KZ and NPG. We would also like to thank the investigative teams from Oxford (Sallet, Mars, Rushworth), Washington University 
(Donahue, Glasser, Van Essen and colleagues), the Allen Institute (Hawrylycz and colleagues), Vanderbilt (Collins, Kaas and colleagues), Queensland (Elston and colleagues) and Lyon (Kennedy and colleagues) for collecting, publishing and making available their original data.

\section{Author contributions}

Conceptualization - SFW, NPG, XJW.

Methodology - SFW, TX, DM, KZ, NPG, XJW.

Software - SFW, TX.

Validation - SFW, MN, LR, NPG, XJW.

Formal Analysis - SFW.

Investigation - NPG, LR, MN, KZ.

Resources - NPG, KZ, XJW.

Writing - original draft preparation - SFW.

Writing - review and editing - all authors.

Visualization - SFW, LR, NPG.

Supervision - NPG, KZ, XJW.

Funding acquisition - SFW, NPG, KZ, XJW.

\section{References}

Allen, M., Poggiali, D., Whitaker, K., Marshall, T.R., Kievit, R.A., 2019. Raincloud plots: a multi-platform tool for robust data visualization. Wellcome open research 4.

Andrews-Hanna, J.R., Smallwood, J., Spreng, R.N., 2014. The default network and self-generated thought: component processes, dynamic control, and clinical relevance. Ann N Y Acad Sci 1316, 29-52. https://doi.org/10.1111/nyas.12360

Anticevic, A., Gancsos, M., Murray, J.D., Repovs, G., Driesen, N.R., Ennis, D.J., Niciu, M.J., Morgan, P.T., Surti, T.S., Bloch, M.H., Ramani, R., Smith, M.A., Wang, X.-J., Krystal, J.H., Corlett, P.R., 2012. NMDA receptor function in large-scale anticorrelated neural systems with implications for cognition and schizophrenia. PNAS 109, 16720-16725. https://doi.org/10.1073/pnas.1208494109

Arnatkeviciute, A., Fulcher, B.D., Fornito, A., 2019. A practical guide to linking brainwide gene expression and neuroimaging data. NeuroImage 189, 353-367. https://doi.org/10.1016/j.neuroimage.2019.01.011

Beliveau, V., Ganz, M., Feng, L., Ozenne, B., Højgaard, L., Fisher, P.M., Svarer, C., Greve, D.N., Knudsen, G.M., 2017. A High-Resolution In Vivo Atlas of the Human Brain's Serotonin System. J. Neurosci. 37, 120-128. https://doi.org/10.1523/JNEUROSCI.2830-16.2016

Braitenberg, V., 1962. A note on myeloarchitectonics. Journal of comparative Neurology 118, 141-156.

Buckner, R.L., Andrews-Hanna, J.R., Schacter, D.L., 2008. The brain's default network: Anatomy, function, and relevance to disease, in: The Year in 
Cognitive Neuroscience 2008, Annals of the New York Academy of Sciences. Blackwell Publishing, Malden, pp. 1-38.

Burt, J.B., Demirtaş, M., Eckner, W.J., Navejar, N.M., Ji, J.L., Martin, W.J., Bernacchia, A., Anticevic, A., Murray, J.D., 2018. Hierarchy of transcriptomic specialization across human cortex captured by structural neuroimaging topography.

Nature Neuroscience 21, 1251. https://doi.org/10.1038/s41593-018-0195-0

Cano-Colino, M., Almeida, R., Gomez-Cabrero, D., Artigas, F., Compte, A., 2014.

Serotonin Regulates Performance Nonmonotonically in a Spatial Working

Memory Network. Cereb Cortex 24, 2449-2463.

https://doi.org/10.1093/cercor/bht096

Carhart-Harris, R., Nutt, D., 2017. Serotonin and brain function: a tale of two receptors. J Psychopharmacol 31, 1091-1120. https://doi.org/10.1177/0269881117725915

Celada, P., Puig, M.V., Artigas, F., 2013. Serotonin modulation of cortical neurons and networks. Front. Integr. Neurosci. 7. https://doi.org/10.3389/fnint.2013.00025

Chai, X.J., Castañón, A.N., Öngür, D., Whitfield-Gabrieli, S., 2012. Anticorrelations in resting state networks without global signal regression. NeuroImage 59, 1420-1428. https://doi.org/10.1016/j.neuroimage.2011.08.048

Chaudhuri, R., Knoblauch, K., Gariel, M.-A., Kennedy, H., Wang, X.-J., 2015. A largescale circuit mechanism for hierarchical dynamical processing in the primate cortex. Neuron 88, 419-431. https://doi.org/10.1016/j.neuron.2015.09.008

Coifman, R.R., Lafon, S., 2006. Diffusion maps. Applied and Computational Harmonic Analysis, Special Issue: Diffusion Maps and Wavelets 21, 5-30. https://doi.org/10.1016/j.acha.2006.04.006

Coletta, L., Pagani, M., Whitesell, J.D., Harris, J.A., Bernhardt, B., Gozzi, A., 2020. Network structure of the mouse brain connectome with voxel resolution. bioRxiv 2020.03.06.973164. https://doi.org/10.1101/2020.03.06.973164

Collins, C.E., Airey, D.C., Young, N.A., Leitch, D.B., Kaas, J.H., 2010. Neuron densities vary across and within cortical areas in primates. Proceedings of the National Academy of Sciences 107, 15927-15932.

Corbetta, M., Shulman, G.L., 2002. Control of goal-directed and stimulus-driven attention in the brain. Nature Reviews Neuroscience 3, 201-215. https://doi.org/10.1038/nrn755

Deco, G., Cruzat, J., Cabral, J., Knudsen, G.M., Carhart-Harris, R.L., Whybrow, P.C., Logothetis, N.K., Kringelbach, M.L., 2018. Whole-Brain Multimodal Neuroimaging Model Using Serotonin Receptor Maps Explains Non-linear Functional Effects of LSD. Current Biology 28, 3065-3074.e6. https://doi.org/10.1016/j.cub.2018.07.083

Dixon, M.L., Vega, A.D.L., Mills, C., Andrews-Hanna, J., Spreng, R.N., Cole, M.W., Christoff, K., 2018. Heterogeneity within the frontoparietal control network and its relationship to the default and dorsal attention networks. PNAS 115, E1598-E1607. https://doi.org/10.1073/pnas.1715766115

Donahue, C.J., Sotiropoulos, S.N., Jbabdi, S., Hernandez-Fernandez, M., Behrens, T.E., Dyrby, T.B., Coalson, T., Kennedy, H., Knoblauch, K., Van Essen, D.C., Glasser, M.F., 2016. Using diffusion tractography to predict cortical connection 
strength and distance: a quantitative comparison with tracers in the monkey. J. Neurosci. 36, 6758-6770.

Elston, G.N., 2001. Interlaminar differences in the pyramidal cell phenotype in cortical areas $7 \mathrm{~m}$ and STP (the superior temporal polysensory area) of the macaque monkey. Exp Brain Res 138, 141-152.

https://doi.org/10.1007/s002210100705

Elston, G.N., 2000. Pyramidal Cells of the Frontal Lobe: All the More Spinous to Think With. J. Neurosci. 20, RC95-RC95. https://doi.org/10.1523/JNEUROSCI.20-18-j0002.2000

Elston, G.N., Benavides-Piccione, R., DeFelipe, J., 2005. A Study of Pyramidal Cell Structure in the Cingulate Cortex of the Macaque Monkey with Comparative Notes on Inferotemporal and Primary Visual Cortex. Cereb Cortex 15, 64-73. https://doi.org/10.1093/cercor/bhh109

Elston, G.N., Benavides-Piccione, R., DeFelipe, J., 2001. The Pyramidal Cell in Cognition: A Comparative Study in Human and Monkey. J. Neurosci. 21, RC163-RC163. https://doi.org/10.1523/JNEUROSCI.21-17-j0002.2001

Elston, G.N., Benavides-Piccione, R., Elston, A., Manger, P., Defelipe, J., 2011a. Pyramidal Cells in Prefrontal Cortex of Primates: Marked Differences in Neuronal Structure Among Species. Front. Neuroanat. 5. https://doi.org/10.3389/fnana.2011.00002

Elston, G.N., Oga, T., Fujita, I., 2009. Spinogenesis and Pruning Scales across Functional Hierarchies. J. Neurosci. 29, 3271-3275. https://doi.org/10.1523/JNEUROSCI.5216-08.2009

Elston, G.N., Oga, T., Okamoto, T., Fujita, I., 2011b. Spinogenesis and Pruning in the Anterior Ventral Inferotemporal Cortex of the Macaque Monkey: An Intracellular Injection Study of Layer III Pyramidal Cells. Front. Neuroanat. 5. https://doi.org/10.3389/fnana.2011.00042

Elston, G.N., Okamoto, T., Oga, T., Dornan, D., Fujita, I., 2010. Spinogenesis and pruning in the primary auditory cortex of the macaque monkey (Macaca fascicularis): an intracellular injection study of layer III pyramidal cells. Brain research $1316,35-42$.

Elston, G.N., Rockland, K.S., 2002. The Pyramidal Cell of the Sensorimotor Cortex of the Macaque Monkey: Phenotypic Variation. Cereb Cortex 12, 1071-1078. https://doi.org/10.1093/cercor/12.10.1071

Elston, G.N., Rosa, M.G., 1998a. Morphological variation of layer III pyramidal neurones in the occipitotemporal pathway of the macaque monkey visual cortex. Cereb Cortex 8, 278-294. https://doi.org/10.1093/cercor/8.3.278

Elston, G.N., Rosa, M.G., 1997. The occipitoparietal pathway of the macaque monkey: comparison of pyramidal cell morphology in layer III of functionally related cortical visual areas. Cereb Cortex 7, 432-452. https://doi.org/10.1093/cercor/7.5.432

Elston, G.N., Rosa, M.G.P., 1998b. Complex dendritic fields of pyramidal cells in the frontal eye field of the macaque monkey: comparison with parietal areas $7 \mathrm{a}$ and LIP. NeuroReport 9, 127.

Elston, G.N., Tweedale, R., Rosa, M.G.P., 1999. Cortical integration in the visual system of the macaque monkey: large-scale morphological differences in the 
pyramidal neurons in the occipital, parietal and temporal lobes. Proceedings of the Royal Society of London B: Biological Sciences 266, 1367-1374. https://doi.org/10.1098/rspb.1999.0789

Felleman, D.J., Van Essen, D., 1991. Distributed hierarchical processing in the primate cerebral cortex. Cereb Cortex 1, 1-47.

https://doi.org/10.1093/cercor/1.1.1

Fox, M.D., Snyder, A.Z., Vincent, J.L., Corbetta, M., Essen, D.C.V., Raichle, M.E., 2005. The human brain is intrinsically organized into dynamic, anticorrelated functional networks. PNAS 102, 9673-9678.

https://doi.org/10.1073/pnas.0504136102

Froudist-Walsh, S., Bliss, D.P., Ding, X., Jankovic-Rapan, L., Niu, M., Knoblauch, K., Zilles, K., Kennedy, H., Palomero-Gallagher, N., Wang, X.-J., 2020. A dopamine gradient controls access to distributed working memory in monkey cortex. bioRxiv 2020.09.07.286500. https://doi.org/10.1101/2020.09.07.286500

Froudist-Walsh, S., Browning, P.G., Young, J.J., Murphy, K.L., Mars, R.B., Fleysher, L., Croxson, P.L., 2018. Macro-connectomics and microstructure predict dynamic plasticity patterns in the non-human primate brain. eLife 7, e34354. https://doi.org/10.7554/eLife.34354

Fulcher, B.D., Murray, J.D., Zerbi, V., Wang, X.-J., 2019. Multimodal gradients across mouse cortex. Proceedings of the National Academy of Sciences 116, 46894695. https://doi.org/10.1073/pnas.1814144116

Gallyas, F., 1979. Silver Staining of Myelin by Means of Physical Development. Neurological Research 1, 203-209. https://doi.org/10.1080/01616412.1979.11739553

Gao, R., van den Brink, R.L., Pfeffer, T., Voytek, B., 2020. Neuronal timescales are functionally dynamic and shaped by cortical microarchitecture. eLife 9, e61277. https://doi.org/10.7554/eLife.61277

Geyer, S., Matelli, M., Luppino, G., Schleicher, A., Jansen, Y., Palomero-Gallagher, N., Zilles, K., 1998. Receptor autoradiographic mapping of the mesial motor and premotor cortex of the macaque monkey. Journal of Comparative Neurology 397, 231-250. https://doi.org/10.1002/(SICI)10969861(19980727)397:2<231::AID-CNE6>3.0.C0;2-1

Glasser, M.F., Coalson, T.S., Robinson, E.C., Hacker, C.D., Harwell, J., Yacoub, E., Ugurbil, K., Andersson, J., Beckmann, C.F., Jenkinson, M., Smith, S.M., Van Essen, D.C., 2016. A multi-modal parcellation of human cerebral cortex. Nature 536, 171-178.

Glasser, M.F., Essen, D.C.V., 2011. Mapping Human Cortical Areas In Vivo Based on Myelin Content as Revealed by T1- and T2-Weighted MRI. J. Neurosci. 31, 11597-11616. https://doi.org/10.1523/JNEUROSCI.2180-11.2011

Glasser, M.F., Sotiropoulos, S.N., Wilson, J.A., Coalson, T.S., Fischl, B., Andersson, J.L., $\mathrm{Xu}$, J., Jbabdi, S., Webster, M., Polimeni, J.R., Van Essen, D.C., Jenkinson, M., 2013. The minimal preprocessing pipelines for the Human Connectome Project. NeuroImage, Mapping the Connectome 80, 105-124. https://doi.org/10.1016/j.neuroimage.2013.04.127 
Goulas, A., Changeux, J.-P., Wagstyl, K., Amunts, K., Palomero-Gallagher, N., Hilgetag, C.C., 2021. The natural axis of transmitter receptor distribution in the human cerebral cortex. PNAS 118. https://doi.org/10.1073/pnas.2020574118

Hasson, U., Yang, E., Vallines, I., Heeger, D.J., Rubin, N., 2008. A hierarchy of temporal receptive windows in human cortex. J. Neurosci. 28, 2539-2550.

Hawrylycz, M.J., Lein, E.S., Guillozet-Bongaarts, A.L., Shen, E.H., Ng, L., Miller, J.A., van de Lagemaat, L.N., Smith, K.A., Ebbert, A., Riley, Z.L., Abajian, C., Beckmann, C.F., Bernard, A., Bertagnolli, D., Boe, A.F., Cartagena, P.M., Chakravarty, M.M., Chapin, M., Chong, J., Dalley, R.A., Daly, B.D., Dang, C., Datta, S., Dee, N., Dolbeare, T.A., Faber, V., Feng, D., Fowler, D.R., Goldy, J., Gregor, B.W., Haradon, Z., Haynor, D.R., Hohmann, J.G., Horvath, S., Howard, R.E., Jeromin, A., Jochim, J.M., Kinnunen, M., Lau, C., Lazarz, E.T., Lee, C., Lemon, T.A., Li, L., Li, Y., Morris, J.A., Overly, C.C., Parker, P.D., Parry, S.E., Reding, M., Royall, J.J., Schulkin, J., Sequeira, P.A., Slaughterbeck, C.R., Smith, S.C., Sodt, A.J., Sunkin, S.M., Swanson, B.E., Vawter, M.P., Williams, D., Wohnoutka, P., Zielke, H.R., Geschwind, D.H., Hof, P.R., Smith, S.M., Koch, C., Grant, S.G.N., Jones, A.R., 2012. An anatomically comprehensive atlas of the adult human brain transcriptome. Nature 489, 391-399. https://doi.org/10.1038/nature11405

Hayashi, T., Hou, Y., Glasser, M.F., Autio, J.A., Knoblauch, K., Inoue-Murayama, M., Coalson, T., Yacoub, E., Smith, S., Kennedy, H., Van Essen, D.C., 2020. The NonHuman Primate Neuroimaging \& Neuroanatomy Project. arXiv:2010.00308 [q-bio].

Herculano-Houzel, S., Lent, R., 2005. Isotropic fractionator: a simple, rapid method for the quantification of total cell and neuron numbers in the brain. Journal of Neuroscience 25, 2518-2521. https://doi.org/10.1523/JNEUROSCI.452604.2005

Hodge, R.D., Bakken, T.E., Miller, J.A., Smith, K.A., Barkan, E.R., Graybuck, L.T., Close, J.L., Long, B., Johansen, N., Penn, O., Yao, Z., Eggermont, J., Höllt, T., Levi, B.P., Shehata, S.I., Aevermann, B., Beller, A., Bertagnolli, D., Brouner, K., Casper, T., Cobbs, C., Dalley, R., Dee, N., Ding, S.-L., Ellenbogen, R.G., Fong, O., Garren, E., Goldy, J., Gwinn, R.P., Hirschstein, D., Keene, C.D., Keshk, M., Ko, A.L., Lathia, K., Mahfouz, A., Maltzer, Z., McGraw, M., Nguyen, T.N., Nyhus, J., Ojemann, J.G., Oldre, A., Parry, S., Reynolds, S., Rimorin, C., Shapovalova, N.V., Somasundaram, S., Szafer, A., Thomsen, E.R., Tieu, M., Quon, G., Scheuermann, R.H., Yuste, R., Sunkin, S.M., Lelieveldt, B., Feng, D., Ng, L., Bernard, A., Hawrylycz, M., Phillips, J.W., Tasic, B., Zeng, H., Jones, A.R., Koch, C., Lein, E.S., 2019. Conserved cell types with divergent features in human versus mouse cortex. Nature 573, 61-68. https://doi.org/10.1038/s41586-019-1506-7

Hoyer, D., Engel, G., Kalkman, H.O., 1985. Molecular pharmacology of 5-HT1 and 5HT2 recognition sites in rat and pig brain membranes: Radioligand binding studies with [3H]5-HT, [3H]8-OH-DPAT, (-)[125I]iodocyanopindolol, $[3 \mathrm{H}]$ mesulergine and $[3 \mathrm{H}]$ Ketanserin. European Journal of Pharmacology 118, 13-23. https://doi.org/10.1016/0014-2999(85)90658-2

Hoyer, D., Pazos, A., Probst, A., Palacios, J.M., 1986a. Serotonin receptors in the human brain. I. Characterization and autoradiographic localization of 5-HT1A 
recognition sites. Apparent absence of 5-HT1B recognition sites. Brain research 376, 85-96.

Hoyer, D., Pazos, A., Probst, A., Palacios, J.M., 1986b. Serotonin receptors in the human brain. II. Characterization and autoradiographic localization of 5HT1C and 5-HT2 recognition sites. Brain research 376, 97-107.

Impieri, D., Zilles, K., Niu, M., Rapan, L., Schubert, N., Galletti, C., Palomero-Gallagher, N., 2019. Receptor density pattern confirms and enhances the anatomicfunctional features of the macaque superior parietal lobule areas. Brain Structure and Function 224, 2733-2756. https://doi.org/10.1007/s00429019-01930-9

Kelly, A.M.C., Uddin, L.Q., Biswal, B.B., Castellanos, F.X., Milham, M.P., 2008. Competition between functional brain networks mediates behavioral variability. NeuroImage 39, 527-537.

https://doi.org/10.1016/j.neuroimage.2007.08.008

Kennedy, H., Knoblauch, K., Toroczkai, Z., 2013. Why data coherence and quality is critical for understanding interareal cortical networks. NeuroImage, Mapping the Connectome 80, 37-45. https://doi.org/10.1016/j.neuroimage.2013.04.031

Kim, Y., Yang, G.R., Pradhan, K., Venkataraju, K.U., Bota, M., García del Molino, L.C., Fitzgerald, G., Ram, K., He, M., Levine, J.M., Mitra, P., Huang, Z.J., Wang, X.-J., Osten, P., 2017. Brain-wide Maps Reveal Stereotyped Cell-Type-Based Cortical Architecture and Subcortical Sexual Dimorphism. Cell 171, 456469.e22. https://doi.org/10.1016/j.cell.2017.09.020

Lu, W.-Y., Man, H.-Y., Ju, W., Trimble, W.S., MacDonald, J.F., Wang, Y.T., 2001. Activation of Synaptic NMDA Receptors Induces Membrane Insertion of New AMPA Receptors and LTP in Cultured Hippocampal Neurons. Neuron 29, 243-254. https://doi.org/10.1016/S0896-6273(01)00194-5

MacKay, A.L., Laule, C., 2016. Magnetic Resonance of Myelin Water: An\&nbsp; in vivo Marker for Myelin. Brain Plasticity 2, 71-91. https://doi.org/10.3233/BPL160033

Majka, P., Bai, S., Bakola, S., Bednarek, S., Chan, J.M., Jermakow, N., Passarelli, L., Reser, D.H., Theodoni, P., Worthy, K.H., Wang, X.-J., Wójcik, D.K., Mitra, P.P., Rosa, M.G.P., 2020. Open access resource for cellular-resolution analyses of corticocortical connectivity in the marmoset monkey. Nature Communications 11, 1133. https://doi.org/10.1038/s41467-020-14858-0

Margulies, D.S., Ghosh, S.S., Goulas, A., Falkiewicz, M., Huntenburg, J.M., Langs, G., Bezgin, G., Eickhoff, S.B., Castellanos, F.X., Petrides, M., Jefferies, E., Smallwood, J., 2016. Situating the default-mode network along a principal gradient of macroscale cortical organization. Proceedings of the National Academy of Sciences 113, 12574-12579. https://doi.org/10.1073/pnas.1608282113

Markov, N.T., Ercsey-Ravasz, M., Essen, D.C.V., Knoblauch, K., Toroczkai, Z., Kennedy, H., 2013. Cortical high-density counterstream architectures. Science 342, 1238406. https://doi.org/10.1126/science.1238406

Markov, N.T., Ercsey-Ravasz, M.M., Ribeiro Gomes, A.R., Lamy, C., Magrou, L., Vezoli, J., Misery, P., Falchier, A., Quilodran, R., Gariel, M.A., Sallet, J., Gamanut, R., 
Huissoud, C., Clavagnier, S., Giroud, P., Sappey-Marinier, D., Barone, P., Dehay, C., Toroczkai, Z., Knoblauch, K., Van Essen, D.C., Kennedy, H., 2014a. A weighted and directed interareal connectivity matrix for macaque cerebral cortex. Cereb Cortex 24, 17-36. https://doi.org/10.1093/cercor/bhs270

Markov, N.T., Vezoli, J., Chameau, P., Falchier, A., Quilodran, R., Huissoud, C., Lamy, C., Misery, P., Giroud, P., Ullman, S., Barone, P., Dehay, C., Knoblauch, K., Kennedy, H., 2014b. Anatomy of hierarchy: Feedforward and feedback pathways in macaque visual cortex. Journal of Comparative Neurology 522, 225-259. https://doi.org/10.1002/cne.23458

Mars, R.B., Jbabdi, S., Sallet, J., O’Reilly, J.X., Croxson, P.L., Olivier, E., Noonan, M.P., Bergmann, C., Mitchell, A.S., Baxter, M.G., Behrens, T.E.J., Johansen-Berg, H., Tomassini, V., Miller, K.L., Rushworth, M.F.S., 2011. Diffusion-Weighted Imaging Tractography-Based Parcellation of the Human Parietal Cortex and Comparison with Human and Macaque Resting-State Functional Connectivity. J. Neurosci. 31, 4087-4100. https://doi.org/10.1523/JNEUROSCI.5102-10.2011

Mars, R.B., Sotiropoulos, S.N., Passingham, R.E., Sallet, J., Verhagen, L., Khrapitchev, A.A., Sibson, N., Jbabdi, S., 2018. Whole brain comparative anatomy using connectivity blueprints. eLife 7, e35237. https://doi.org/10.7554/eLife.35237

Matias, S., Lottem, E., Dugué, G.P., Mainen, Z.F., 2017. Activity patterns of serotonin neurons underlying cognitive flexibility. eLife 6, e20552. https://doi.org/10.7554/eLife.20552

Mayberg, H.S., 2003. Positron emission tomography imaging in depression: a neural systems perspective. Neuroimaging Clinics 13, 805-815.

https://doi.org/10.1016/S1052-5149(03)00104-7

Mayberg, H.S., 1997. Limbic-cortical dysregulation: A proposed model of depression. The Journal of Neuropsychiatry and Clinical Neurosciences 9, 471-481. https://doi.org/10.1176/jnp.9.3.471

Mayberg, H.S., Brannan, S.K., Tekell, J.L., Silva, J.A., Mahurin, R.K., McGinnis, S., Jerabek, P.A., 2000. Regional metabolic effects of fluoxetine in major depression: serial changes and relationship to clinical response. Biological Psychiatry 48, 830-843. https://doi.org/10.1016/S0006-3223(00)01036-2

Mayberg, H.S., Lozano, A.M., Voon, V., McNeely, H.E., Seminowicz, D., Hamani, C., Schwalb, J.M., Kennedy, S.H., 2005. Deep Brain Stimulation for TreatmentResistant Depression. Neuron 45, 651-660. https://doi.org/10.1016/j.neuron.2005.02.014

McGee, A.W., Yang, Y., Fischer, Q.S., Daw, N.W., Strittmatter, S.M., 2005. ExperienceDriven Plasticity of Visual Cortex Limited by Myelin and Nogo Receptor. Science 309, 2222-2226. https://doi.org/10.1126/science.1114362

McIlwain, H., Bachelard, H.S., 1972. Biochemistry and the central nervous system.

Megías, M., Emri, Z., Freund, T.F., Gulyás, A.I., 2001. Total number and distribution of inhibitory and excitatory synapses on hippocampal CA1 pyramidal cells. Neuroscience 102, 527-540. https://doi.org/10.1016/S03064522(00)00496-6 
Menon, V., 2015. Salience Network, in: Brain Mapping. Elsevier, pp. 597-611. https://doi.org/10.1016/B978-0-12-397025-1.00052-X

Menon, V., 2011. Large-scale brain networks and psychopathology: a unifying triple network model. Trends in Cognitive Sciences 15, 483-506. https://doi.org/10.1016/j.tics.2011.08.003

Menon, V., Uddin, L.Q., 2010. Saliency, switching, attention and control: a network model of insula function. Brain Struct Funct 214, 655-667. https://doi.org/10.1007/s00429-010-0262-0

Merker, B., 1983. Silver staining of cell bodies by means of physical development. Journal of Neuroscience Methods 9, 235-241. https://doi.org/10.1016/0165-0270(83)90086-9

Milham, M., Petkov, C.I., Margulies, D.S., Schroeder, C.E., Basso, M.A., Belin, P., Fair, D.A., Fox, A., Kastner, S., Mars, R.B., Messinger, A., Poirier, C., Vanduffel, W., Van Essen, D.C., Alvand, A., Becker, Y., Ben Hamed, S., Benn, A., Bodin, C., Boretius, S., Cagna, B., Coulon, O., El-Gohary, S.H., Evrard, H., Forkel, S.J., Friedrich, P., Froudist-Walsh, S., Garza-Villarreal, E.A., Gao, Y., Gozzi, A., Grigis, A., Hartig, R., Hayashi, T., Heuer, K., Howells, H., Ardesch, D.J., Jarraya, B., Jarrett, W., Jedema, H.P., Kagan, I., Kelly, C., Kennedy, H., Klink, P.C., Kwok, S.C., Leech, R., Liu, X., Madan, C., Madushanka, W., Majka, P., Mallon, A.-M., Marche, K., Meguerditchian, A., Menon, R.S., Merchant, H., Mitchell, A., Nenning, K.-H., Nikolaidis, A., Ortiz-Rios, M., Pagani, M., Pareek, V., Prescott, M., Procyk, E., Rajimehr, R., Rautu, I.-S., Raz, A., Roe, A.W., Rossi-Pool, R., Roumazeilles, L., Sakai, T., Sallet, J., García-Saldivar, P., Sato, C., Sawiak, S., Schiffer, M., Schwiedrzik, C.M., Seidlitz, J., Sein, J., Shen, Z., Shmuel, A., Silva, A.C., Simone, L., Sirmpilatze, N., Sliwa, J., Smallwood, J., Tasserie, J., Thiebaut de Schotten, M., Toro, R., Trapeau, R., Uhrig, L., Vezoli, J., Wang, Z., Wells, S., Williams, B., Xu, T., Xu, A.G., Yacoub, E., Zhan, M., Ai, L., Amiez, C., Balezeau, F., Baxter, M.G., Blezer, E.L.A., Brochier, T., Chen, A., Croxson, P.L., Damatac, C.G., Dehaene, S., Everling, S., Fleysher, L., Freiwald, W., Griffiths, T.D., Guedj, C., Hadj-Bouziane, F., Harel, N., Hiba, B., Jung, B., Koo, B., Laland, K.N., Leopold, D.A., Lindenfors, P., Meunier, M., Mok, K., Morrison, J.H., Nacef, J., Nagy, J., Pinsk, M., Reader, S.M., Roelfsema, P.R., Rudko, D.A., Rushworth, M.F.S., Russ, B.E., Schmid, M.C., Sullivan, E.L., Thiele, A., Todorov, O.S., Tsao, D., Ungerleider, L., Wilson, C.R.E., Ye, F.Q., Zarco, W., Zhou, Y., 2020. Accelerating the Evolution of Nonhuman Primate Neuroimaging. Neuron 105, 600-603. https://doi.org/10.1016/j.neuron.2019.12.023

Milham, M.P., Ai, L., Koo, B., Xu, T., Amiez, C., Balezeau, F., Baxter, M.G., Blezer, E.L.A., Brochier, T., Chen, A., Croxson, P.L., Damatac, C.G., Dehaene, S., Everling, S., Fair, D.A., Fleysher, L., Freiwald, W., Froudist-Walsh, S., Griffiths, T.D., Guedj, C., Hadj-Bouziane, F., Ben Hamed, S., Harel, N., Hiba, B., Jarraya, B., Jung, B., Kastner, S., Klink, P.C., Kwok, S.C., Laland, K.N., Leopold, D.A., Lindenfors, P., Mars, R.B., Menon, R.S., Messinger, A., Meunier, M., Mok, K., Morrison, J.H., Nacef, J., Nagy, J., Rios, M.O., Petkov, C.I., Pinsk, M., Poirier, C., Procyk, E., Rajimehr, R., Reader, S.M., Roelfsema, P.R., Rudko, D.A., Rushworth, M.F.S., Russ, B.E., Sallet, J., Schmid, M.C., Schwiedrzik, C.M., Seidlitz, J., Sein, J., Shmuel, A., Sullivan, E.L., Ungerleider, L., Thiele, A., Todorov, O.S., Tsao, D., Wang, Z., 
Wilson, C.R.E., Yacoub, E., Ye, F.Q., Zarco, W., Zhou, Y., Margulies, D.S., Schroeder, C.E., 2018. An Open Resource for Non-human Primate Imaging. Neuron 100, 61-74.e2. https://doi.org/10.1016/j.neuron.2018.08.039

Murray, J.D., Bernacchia, A., Freedman, D.J., Romo, R., Wallis, J.D., Cai, X., PadoaSchioppa, C., Pasternak, T., Seo, H., Lee, D., Wang, X.-J., 2014. A hierarchy of intrinsic timescales across primate cortex. Nature Neuroscience 17, 16611663. https://doi.org/10.1038/nn.3862

Neubert, F.-X., Mars, R.B., Thomas, A.G., Sallet, J., Rushworth, M.F.S., 2014. Comparison of Human Ventral Frontal Cortex Areas for Cognitive Control and Language with Areas in Monkey Frontal Cortex. Neuron 81, 700-713. https://doi.org/10.1016/j.neuron.2013.11.012

Niu, M., Impieri, D., Rapan, L., Funck, T., Palomero-Gallagher, N., Zilles, K., 2020. Receptor-driven, multimodal mapping of cortical areas in the macaque monkey intraparietal sulcus. eLife 9, e55979. https://doi.org/10.7554/eLife.55979

Niu, M., Rapan, L., Funck, T., Froudist-Walsh, S., Zhao, L., Zilles, K., PalomeroGallagher, N., 2021. Organization of the Macaque Monkey Inferior Parietal Lobule Based on Multimodal Receptor Architectonics. NeuroImage 117843. https://doi.org/10.1016/j.neuroimage.2021.117843

Noonan, M.P., Sallet, J., Mars, R.B., Neubert, F.X., O’Reilly, J.X., Andersson, J.L., Mitchell, A.S., Bell, A.H., Miller, K.L., Rushworth, M.F.S., 2014. A Neural Circuit Covarying with Social Hierarchy in Macaques. PLOS Biology 12, e1001940. https://doi.org/10.1371/journal.pbio.1001940

Oh, S.W., Harris, J.A., Ng, L., Winslow, B., Cain, N., Mihalas, S., Wang, Q., Lau, C., Kuan, L., Henry, A.M., Mortrud, M.T., Ouellette, B., Nguyen, T.N., Sorensen, S.A., Slaughterbeck, C.R., Wakeman, W., Li, Y., Feng, D., Ho, A., Nicholas, E., Hirokawa, K.E., Bohn, P., Joines, K.M., Peng, H., Hawrylycz, M.J., Phillips, J.W., Hohmann, J.G., Wohnoutka, P., Gerfen, C.R., Koch, C., Bernard, A., Dang, C., Jones, A.R., Zeng, H., 2014. A mesoscale connectome of the mouse brain. Nature 508, 207-214.

Palomero-Gallagher, N., Zilles, K., 2018a. Chapter 24 - Cyto- and receptor architectonic mapping of the human brain, in: Huitinga, I., Webster, M.J. (Eds.), Handbook of Clinical Neurology, Brain Banking. Elsevier, pp. 355-387. https://doi.org/10.1016/B978-0-444-63639-3.00024-4

Palomero-Gallagher, N., Zilles, K., 2018b. Chapter 24 - Cyto- and receptor architectonic mapping of the human brain, in: Huitinga, I., Webster, M.J. (Eds.), Handbook of Clinical Neurology, Brain Banking. Elsevier, pp. 355-387. https://doi.org/10.1016/B978-0-444-63639-3.00024-4

Preuss, T.M., Goldman-Rakic, P.S., 1991. Myelo- and cytoarchitecture of the granular frontal cortex and surrounding regions in the strepsirhine primate Galago and the anthropoid primate Macaca. Journal of Comparative Neurology 310, 429-474. https://doi.org/10.1002/cne.903100402

Puig, M.V., Gulledge, A.T., 2011. Serotonin and Prefrontal Cortex Function: Neurons, Networks, and Circuits. Mol Neurobiol 44, 449-464. https://doi.org/10.1007/s12035-011-8214-0 
Puig, M.V., Watakabe, A., Ushimaru, M., Yamamori, T., Kawaguchi, Y., 2010. Serotonin Modulates Fast-Spiking Interneuron and Synchronous Activity in the Rat Prefrontal Cortex through 5-HT1A and 5-HT2A Receptors. J. Neurosci. 30, 2211-2222. https://doi.org/10.1523/JNEUROSCI.3335-09.2010

Raichle, M.E., 2015. The Brain's Default Mode Network. Annual Review of Neuroscience 38, 433-447. https://doi.org/10.1146/annurev-neuro071013-014030

Rapan, L., Froudist-Walsh, S., Niu, M., Xu, T., Funck, T., Zilles, K., Palomero-Gallagher, N., 2020. Multimodal 3D atlas of the macaque monkey motor and premotor cortex. NeuroImage 117574.

Raut, R.V., Snyder, A.Z., Raichle, M.E., 2020. Hierarchical dynamics as a macroscopic organizing principle of the human brain. PNAS 117, 20890-20897. https://doi.org/10.1073/pnas.2003383117

Robinson, E.C., Jbabdi, S., Glasser, M.F., Andersson, J., Burgess, G.C., Harms, M.P., Smith, S.M., Van Essen, D.C., Jenkinson, M., 2014. MSM: A new flexible framework for Multimodal Surface Matching. NeuroImage 100, 414-426. https://doi.org/10.1016/j.neuroimage.2014.05.069

Sallet, J., Mars, R.B., Noonan, M.P., Neubert, F.-X., Jbabdi, S., O’Reilly, J.X., Filippini, N., Thomas, A.G., Rushworth, M.F., 2013. The Organization of Dorsal Frontal Cortex in Humans and Macaques. J. Neurosci. 33, 12255-12274. https://doi.org/10.1523/JNEUROSCI.5108-12.2013

Sanides, F., 1962. Die Architektonik des Menschlichen Stirnhirns: Zugleich eine Darstellung der Prinzipien Seiner Gestaltung als Spiegel der Stammesgeschichtlichen Differenzierung der Grosshirnrinde, Monographien aus dem Gesamtgebiete der Neurologie und Psychiatrie. Springer-Verlag, Berlin Heidelberg. https://doi.org/10.1007/978-3-642-86210-6

Scheffer, L.K., Xu, C.S., Januszewski, M., Lu, Z., Takemura, Shin-ya, Hayworth, K.J., Huang, G.B., Shinomiya, K., Maitlin-Shepard, J., Berg, S., Clements, J., Hubbard, P.M., Katz, W.T., Umayam, L., Zhao, T., Ackerman, D., Blakely, T., Bogovic, J., Dolafi, T., Kainmueller, D., Kawase, T., Khairy, K.A., Leavitt, L., Li, P.H., Lindsey, L., Neubarth, N., Olbris, D.J., Otsuna, H., Trautman, E.T., Ito, M., Bates, A.S., Goldammer, J., Wolff, T., Svirskas, R., Schlegel, P., Neace, E., Knecht, C.J., Alvarado, C.X., Bailey, D.A., Ballinger, S., Borycz, J.A., Canino, B.S., Cheatham, N., Cook, M., Dreher, M., Duclos, O., Eubanks, B., Fairbanks, K., Finley, S., Forknall, N., Francis, A., Hopkins, G.P., Joyce, E.M., Kim, S., Kirk, N.A., Kovalyak, J., Lauchie, S., Lohff, A., Maldonado, C., Manley, E.A., McLin, S., Mooney, C., Ndama, M., Ogundeyi, O., Okeoma, N., Ordish, C., Padilla, N., Patrick, C.M., Paterson, T., Phillips, E.E., Phillips, E.M., Rampally, N., Ribeiro, C., Robertson, M.K., Rymer, J.T., Ryan, S.M., Sammons, M., Scott, A.K., Scott, A.L., Shinomiya, A., Smith, C., Smith, K., Smith, N.L., Sobeski, M.A., Suleiman, A., Swift, J., Takemura, Satoko, Talebi, I., Tarnogorska, D., Tenshaw, E., Tokhi, T., Walsh, J.J., Yang, T., Horne, J.A., Li, F., Parekh, R., Rivlin, P.K., Jayaraman, V., Costa, M., Jefferis, G.S., Ito, K., Saalfeld, S., George, R., Meinertzhagen, I., Rubin, G.M., Hess, H.F., Jain, V., Plaza, S.M., 2020. A connectome and analysis of the adult Drosophila central brain. eLife 9, e57443.

https://doi.org/10.7554/eLife.57443 
Scholtens, L.H., Schmidt, R., Reus, M.A. de, Heuvel, M.P. van den, 2014. Linking Macroscale Graph Analytical Organization to Microscale Neuroarchitectonics in the Macaque Connectome. J. Neurosci. 34, 12192-12205. https://doi.org/10.1523/JNEUROSCI.0752-14.2014

Schwanhäusser, B., Busse, D., Li, N., Dittmar, G., Schuchhardt, J., Wolf, J., Chen, W., Selbach, M., 2011. Global quantification of mammalian gene expression control. Nature 473, 337-342. https://doi.org/10.1038/nature10098

Seltzer, B., Pandya, D.N., 1978. Afferent cortical connections and architectonics of the superior temporal sulcus and surrounding cortex in the rhesus monkey. Brain Research 149, 1-24. https://doi.org/10.1016/0006-8993(78)90584-X

Shine, J.M., Breakspear, M., Bell, P.T., Martens, K.A.E., Shine, R., Koyejo, O., Sporns, O., Poldrack, R.A., 2019. Human cognition involves the dynamic integration of neural activity and neuromodulatory systems. Nature Neuroscience 22, 289296. https://doi.org/10.1038/s41593-018-0312-0

Shulman, G.L., Fiez, J.A., Corbetta, M., Buckner, R.L., Miezin, F.M., Raichle, M.E., Petersen, S.E., 1997. Common Blood Flow Changes across Visual Tasks: II. Decreases in Cerebral Cortex. J Cogn Neurosci 9, 648-663.

https://doi.org/10.1162/jocn.1997.9.5.648

Spreng, R.N., Grady, C.L., 2009. Patterns of Brain Activity Supporting Autobiographical Memory, Prospection, and Theory of Mind, and Their Relationship to the Default Mode Network. Journal of Cognitive Neuroscience 22, 1112-1123. https://doi.org/10.1162/jocn.2009.21282

Spreng, R.N., Stevens, W.D., Chamberlain, J.P., Gilmore, A.W., Schacter, D.L., 2010. Default network activity, coupled with the frontoparietal control network, supports goal-directed cognition. NeuroImage 53, 303-317. https://doi.org/10.1016/j.neuroimage.2010.06.016

Spruston, N., 2008. Pyramidal neurons: dendritic structure and synaptic integration. Nat Rev Neurosci 9, 206-221. https://doi.org/10.1038/nrn2286

Theodoni, P., Majka, P., Reser, D.H., Wójcik, D.K., Rosa, M.G.P., Wang, X.-J., 2020. Structural attributes and principles of the neocortical connectome in the marmoset monkey. bioRxiv 2020.02.28.969824. https://doi.org/10.1101/2020.02.28.969824

Uddin, L.Q., Yeo, B.T.T., Spreng, R.N., 2019. Towards a Universal Taxonomy of Macroscale Functional Human Brain Networks. Brain Topogr 32, 926-942. https://doi.org/10.1007/s10548-019-00744-6

Van Essen, D.C., Dierker, D.L., 2007. Surface-Based and Probabilistic Atlases of Primate Cerebral Cortex. Neuron 56, 209-225. https://doi.org/10.1016/j.neuron.2007.10.015

Van Essen, D.C., Smith, J., Glasser, M.F., Elam, J., Donahue, C.J., Dierker, D.L., Reid, E.K., Coalson, T., Harwell, J., 2017. The Brain Analysis Library of Spatial maps and Atlases (BALSA) database. NeuroImage, Data Sharing Part II 144, 270-274. https://doi.org/10.1016/j.neuroimage.2016.04.002

Wang, X.-J., 2020. Macroscopic gradients of synaptic excitation and inhibition in the neocortex. Nature Reviews Neuroscience 21, 169-178. https://doi.org/10.1038/s41583-020-0262-x 
Wang, X.-J., Pereira, U., Rosa, M.G., Kennedy, H., 2020. Brain connectomes come of age. Current Opinion in Neurobiology, Whole-brain interactions between neural circuits 65, 152-161. https://doi.org/10.1016/j.conb.2020.11.002

White, J.G., Southgate, E., Thomson, J.N., Brenner, S., 1986. The structure of the nervous system of the nematode Caenorhabditis elegans. Philos Trans R Soc Lond B Biol Sci 314, 1-340.

Xiang, Z., Prince, D.A., 2003. Heterogeneous Actions of Serotonin on Interneurons in Rat Visual Cortex. Journal of Neurophysiology 89, 1278-1287. https://doi.org/10.1152/jn.00533.2002

Xu, F., Wu, Q., Xie, L., Gong, W., Zhang, J., Zheng, P., Zhou, Q., Ji, Y., Wang, T., Li, X., Fang, L., Li, Q., Yang, D., Li, J., Melgiri, N.D., Shively, C., Xie, P., 2015. Macaques Exhibit a Naturally-Occurring Depression Similar to Humans. Scientific Reports 5, 9220. https://doi.org/10.1038/srep09220

Xu, T., Falchier, A., Sullivan, E.L., Linn, G., Ramirez, J.S.B., Ross, D., Feczko, E., Opitz, A., Bagley, J., Sturgeon, D., Earl, E., Miranda-Domínguez, O., Perrone, A., Craddock, R.C., Schroeder, C.E., Colcombe, S., Fair, D.A., Milham, M.P., 2018. Delineating the Macroscale Areal Organization of the Macaque Cortex In Vivo. Cell Reports 23, 429-441. https://doi.org/10.1016/j.celrep.2018.03.049

Xu, T., Nenning, K.-H., Schwartz, E., Hong, S.-J., Vogelstein, J.T., Goulas, A., Fair, D.A., Schroeder, C.E., Margulies, D.S., Smallwood, J., Milham, M.P., Langs, G., 2020. Cross-species functional alignment reveals evolutionary hierarchy within the connectome. NeuroImage 223, 117346. https://doi.org/10.1016/j.neuroimage.2020.117346

$\mathrm{Xu}, \mathrm{T}$., Sturgeon, D., Ramirez, J.S.B., Froudist-Walsh, S., Margulies, D.S., Schroeder, C.E., Fair, D.A., Milham, M.P., 2019. Interindividual Variability of Functional Connectivity in Awake and Anesthetized Rhesus Macaque Monkeys. Biological Psychiatry: Cognitive Neuroscience and Neuroimaging, The Bridging of Scales: Techniques for Translational Neuroscience 4, 543-553. https://doi.org/10.1016/j.bpsc.2019.02.005

Yeo, B.T.T., Krienen, F.M., Sepulcre, J., Sabuncu, M.R., Lashkari, D., Hollinshead, M., Roffman, J.L., Smoller, J.W., Zöllei, L., Polimeni, J.R., Fischl, B., Liu, H., Buckner, R.L., 2011. The organization of the human cerebral cortex estimated by intrinsic functional connectivity. Journal of Neurophysiology 106, 11251165. https://doi.org/10.1152/jn.00338.2011

Yeo, B.T.T., Tandi, J., Chee, M.W.L., 2015. Functional connectivity during rested wakefulness predicts vulnerability to sleep deprivation. NeuroImage 111, 147-158. https://doi.org/10.1016/j.neuroimage.2015.02.018

Zilles, K., Palomero-Gallagher, N., 2017a. Comparative analysis of receptor types that identify primary cortical sensory areas., in: Evolution of Nervous Systems. pp. 225-245.

Zilles, K., Palomero-Gallagher, N., 2017b. Multiple Transmitter Receptors in Regions and Layers of the Human Cerebral Cortex. Front. Neuroanat. 11. https://doi.org/10.3389/fnana.2017.00078

Zilles, K., Palomero-Gallagher, N., Grefkes, C., Scheperjans, F., Boy, C., Amunts, K., Schleicher, A., 2002a. Architectonics of the human cerebral cortex and transmitter receptor fingerprints: reconciling functional neuroanatomy and 
neurochemistry. European Neuropsychopharmacology 12, 587-599. https://doi.org/10.1016/S0924-977X(02)00108-6

Zilles, K., Schleicher, A., Palomero-Gallagher, N., Amunts, K., 2002b. Quantitative analysis of cyto-and receptor architecture of the human brain, in: Brain Mapping: The Methods (Second Edition). Elsevier, pp. 573-602. 


\section{Supplementary Figures:}

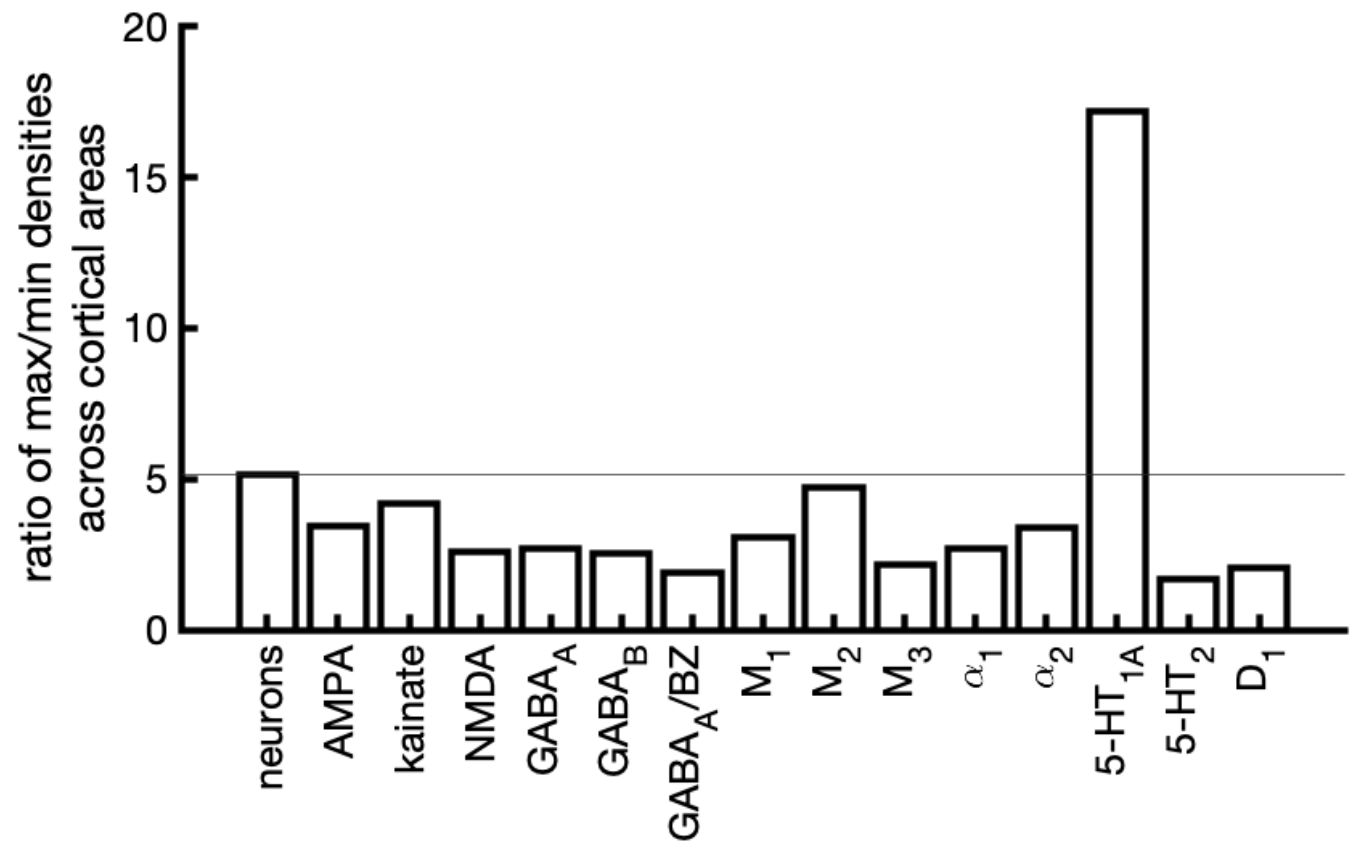

Figure S1. A steep gradient of 5-HT 1 receptors in macaque cortex. The ratio of densities for neurons and each receptor type, formed by the area with maximum density divided by the area with minimal density.
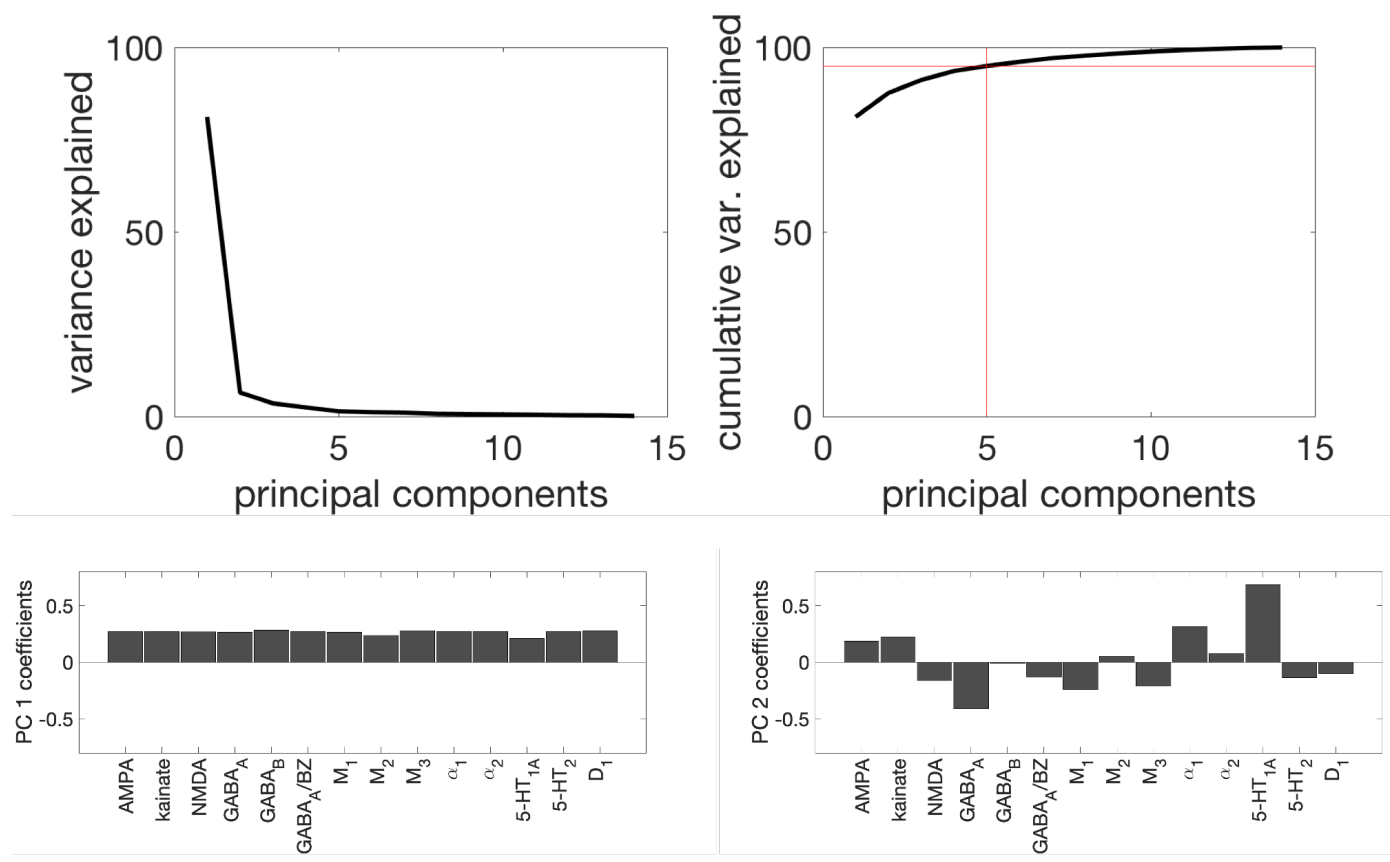

Figure S2. Principal components of the receptor data. Top. The variance explained (left) and cumulative variance explained (right) of each principal component. The top five principal components explained $95 \%$ of the variance in the data. The principal component coefficients for each receptor type contributing to principal component 1 (left) and principal component 2 (right). 

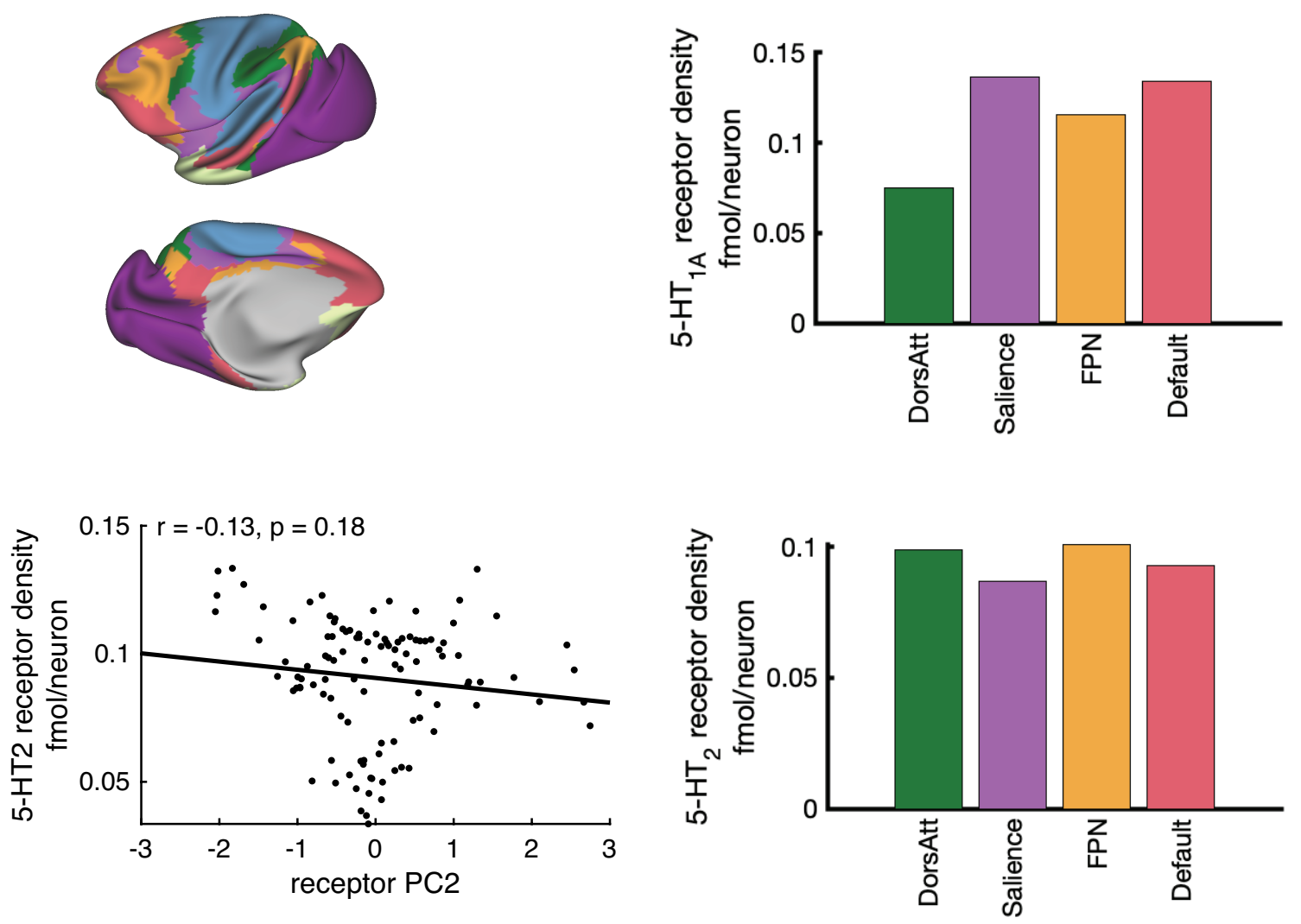

Figure S3. The serotonin $5-\mathrm{HT}_{1 \mathrm{~A}}$ and $5-\mathrm{HT}_{2}$ receptor density in higher cognitive networks. Top-left. The Yeo-Krienen et al cognitive networks in macaque cortex). Right. The mean receptor density for 5-HT ${ }_{1 \mathrm{~A}}$ receptors and 5-HT $\mathrm{T}_{2}$ receptors in the higher cognitive networks. Note, both receptor types were weakly expressed (per neuron) in the sensory networks. Bottom-left. There was no significant correlation between 5-HT2 expression and receptor PC2. 
Supplementary Table 1. Overlap of regions of the Julich Macaque Brain Atlas with the 7 cognitive networks of Yeo, Krienen et al in the macaque cortex. Overlap is expressed as a fraction.

$\begin{array}{lrrrrrrr} & \text { Visual } & \text { SomMot } & \text { DorsAtt } & \text { Salience } & \text { Limbic } & \text { FPN } & \text { Default } \\ 10 \mathrm{~d} & 0 & 0 & 0 & 0 & 0.34 & 0 & 0.66 \\ 10 \mathrm{md} & 0 & 0 & 0 & 0 & 0 & 0 & 1 \\ 10 \mathrm{mv} & 0 & 0 & 0 & 0 & 0.11 & 0 & 0.89 \\ 10 \mathrm{o} & 0 & 0 & 0 & 0 & 0.28 & 0 & 0.72 \\ 11 \mathrm{l} & 0 & 0 & 0 & 0 & 0.83 & 0.17 & 0 \\ 11 \mathrm{~m} & 0 & 0 & 0 & 0 & 0.9 & 0 & 0.1 \\ 12 \mathrm{l} & 0 & 0 & 0 & 0 & 0 & 0 & 1 \\ 12 \mathrm{~m} & 0 & 0 & 0 & 0.05 & 0 & 0.7 & 0.25 \\ 12 \mathrm{o} & 0 & 0 & 0 & 0.02 & 0.24 & 0.03 & 0.7 \\ 12 \mathrm{r} & 0 & 0 & 0 & 0 & 0.26 & 0.14 & 0.6 \\ 13 \mathrm{~b} & 0 & 0 & 0 & 0 & 0.99 & 0 & 0.01 \\ 13 \mathrm{l} & 0 & 0 & 0 & 0 & 1 & 0 & 0 \\ 13 \mathrm{~m} & 0 & 0 & 0 & 0 & 1 & 0 & 0 \\ 14 \mathrm{r} & 0 & 0 & 0 & 0 & 0.78 & 0 & 0.22 \\ 44 & 0 & 0 & 0.45 & 0 & 0 & 0.34 & 0.21 \\ 45 \mathrm{~A} & 0 & 0 & 0 & 0 & 0 & 0.25 & 0.75 \\ 45 \mathrm{~B} & 0 & 0 & 0 & 0 & 0 & 0.62 & 0.38 \\ 4 \mathrm{a} & 0 & 0.87 & 0.1 & 0.03 & 0 & 0 & 0 \\ 4 \mathrm{~m} & 0 & 1 & 0 & 0 & 0 & 0 & 0 \\ 4 \mathrm{p} & 0 & 0.99 & 0 & 0.01 & 0 & 0 & 0 \\ 8 \mathrm{Ad} & 0 & 0 & 0 & 0.27 & 0 & 0.72 & 0.01 \\ 8 \mathrm{Av} & 0 & 0 & 0.01 & 0 & 0 & 0.98 & 0.01 \\ 8 \mathrm{Bd} & 0 & 0 & 0 & 0 & 0 & 0 & 1 \\ 8 \mathrm{Bm} & 0 & 0 & 0 & 0 & 0 & 0 & 1\end{array}$




\begin{tabular}{|c|c|c|c|c|c|c|c|}
\hline $8 \mathrm{Bs}$ & 0 & 0 & 0 & 0.25 & 0 & 0.35 & 0.4 \\
\hline $9 d$ & 0 & 0 & 0 & 0.14 & 0 & 0.08 & 0.78 \\
\hline 9m & 0 & 0 & 0 & 0 & 0 & 0 & 1 \\
\hline a46d & 0 & 0 & 0 & 0 & 0 & 0.53 & 0.47 \\
\hline $\mathrm{a} 46 \mathrm{dr}$ & 0 & 0 & 0 & 0 & 0.05 & 0.27 & 0.67 \\
\hline $\mathrm{a} 46 \mathrm{v}$ & 0 & 0 & 0 & 0 & 0 & 0.79 & 0.21 \\
\hline a46vr & 0 & 0 & 0 & 0 & 0.07 & 0.25 & 0.68 \\
\hline F2d & 0 & 0.21 & 0.48 & 0.07 & 0 & 0.24 & 0 \\
\hline $\mathrm{F} 2 \mathrm{v}$ & 0 & 0.02 & 0.5 & 0 & 0 & 0.18 & 0.3 \\
\hline F3 & 0 & 0.3 & 0 & 0.42 & 0 & 0.06 & 0.22 \\
\hline F4d & 0 & 0.36 & 0.63 & 0.02 & 0 & 0 & 0 \\
\hline $\mathrm{F} 4 \mathrm{~s}$ & 0 & 0 & 0.68 & 0 & 0 & 0.32 & 0 \\
\hline F4v & 0 & 0.1 & 0 & 0.9 & 0 & 0 & 0 \\
\hline $\mathrm{F} 5 \mathrm{~d}$ & 0 & 0 & 0 & 0.67 & 0 & 0.22 & 0.12 \\
\hline F5s & 0 & 0 & 0.44 & 0.12 & 0 & 0.13 & 0.31 \\
\hline F5v & 0 & 0 & 0 & 0.35 & 0 & 0.08 & 0.57 \\
\hline F6 & 0 & 0 & 0 & 0 & 0 & 0.23 & 0.77 \\
\hline $\mathrm{F} 7 \mathrm{~d}$ & 0 & 0 & 0 & 0 & 0 & 0.18 & 0.82 \\
\hline F7i & 0 & 0 & 0 & 0 & 0 & 0.11 & 0.89 \\
\hline $\mathrm{F} 7 \mathrm{~s}$ & 0 & 0 & 0 & 0 & 0 & 0.08 & 0.92 \\
\hline p46d & 0 & 0 & 0 & 0 & 0 & 1 & 0 \\
\hline p46dr & 0 & 0 & 0 & 0.58 & 0 & 0.42 & 0 \\
\hline $\mathrm{p} 46 \mathrm{v}$ & 0 & 0 & 0 & 0 & 0 & 1 & 0 \\
\hline $\mathrm{p} 46 \mathrm{vr}$ & 0 & 0 & 0 & 0 & 0 & 0.67 & 0.33 \\
\hline 1 & 0 & 0.92 & 0 & 0.08 & 0 & 0 & 0 \\
\hline 2 & 0 & 0.98 & 0 & 0.02 & 0 & 0 & 0 \\
\hline 3al & 0 & 0.81 & 0 & 0.17 & 0 & 0.01 & 0.02 \\
\hline 3am & 0 & 1 & 0 & 0 & 0 & 0 & 0 \\
\hline 3bl & 0 & 0.93 & 0 & 0.06 & 0 & 0 & 0 \\
\hline
\end{tabular}




$\begin{array}{lrrrrrrr}\text { 3bm } & 0 & 1 & 0 & 0 & 0 & 0 & 0 \\ \text { AIP } & 0 & 0.05 & 0.95 & 0 & 0 & 0 & 0 \\ \text { DP } & 0.42 & 0 & 0.55 & 0 & 0 & 0.03 & 0 \\ \text { LIPd } & 0 & 0 & 0.82 & 0 & 0 & 0.18 & 0 \\ \text { LIPv } & 0 & 0 & 1 & 0 & 0 & 0 & 0 \\ \text { LOP } & 0 & 0 & 1 & 0 & 0 & 0 & 0 \\ \text { MIPd } & 0 & 0.47 & 0.53 & 0 & 0 & 0 & 0 \\ \text { MIPv } & 0 & 0.06 & 0.94 & 0 & 0 & 0 & 0 \\ \text { Opt } & 0 & 0 & 0.29 & 0 & 0 & 0.71 & 0 \\ \text { PEc } & 0 & 0.31 & 0.69 & 0 & 0 & 0 & 0 \\ \text { PEci } & 0 & 1 & 0 & 0 & 0 & 0 & 0 \\ \text { PEipe } & 0 & 0.79 & 0.21 & 0 & 0 & 0 & 0 \\ \text { PEipi } & 0 & 0.08 & 0.92 & 0 & 0 & 0 & 0 \\ \text { PEI } & 0 & 0.92 & 0.08 & 0 & 0 & 0 & 0 \\ \text { PEla } & 0 & 1 & 0 & 0 & 0 & 0 & 0 \\ \text { PF } & 0 & 0.23 & 0.43 & 0.34 & 0 & 0 & 0 \\ \text { PFG } & 0 & 0 & 1 & 0 & 0 & 0 & 0 \\ \text { PFop } & 0 & 0.36 & 0.06 & 0.58 & 0 & 0 & 0 \\ \text { PG } & 0 & 0 & 0.75 & 0 & 0 & 0.25 & 0 \\ \text { PGm } & 0 & 0 & 0.3 & 0.5 & 0 & 0.02 & 0.18 \\ \text { PGop } & 0 & 0 & 0.65 & 0.31 & 0 & 0.04 & 0 \\ \text { PIP } & 0.02 & 0 & 0.98 & 0 & 0 & 0 & 0 \\ \text { PPt } & 0 & 0 & 0.02 & 0 & 0 & 0.98 & 0 \\ \text { TSA } & 0 & 1 & 0 & 0 & 0 & 0 & 0 \\ \text { V6Adl } & 0 & 0 & 1 & 0 & 0 & 0 & 0 \\ \text { V6Adm } & 0 & 0 & 0.31 & 0 & 0 & 0.4 & 0.29 \\ \text { V6Avl } & 0 & 0 & 0.95 & 0 & 0 & 0.05 & 0 \\ \text { V6Avm } & 0.01 & 0 & 0.01 & 0 & 0 & 0.53 & 0.45 \\ \text { V6I } & 0.57 & 0 & 0.43 & 0 & 0 & 0 & 0 \\ & & 0.93 & 0.95\end{array}$




$\begin{array}{lrrrrrrr}\text { V6m } & 0.72 & 0 & 0.04 & 0 & 0 & 0.23 & 0 \\ \text { VIP } & 0 & 0.02 & 0.98 & 0 & 0 & 0 & 0 \\ \text { V1 } & 1 & 0 & 0 & 0 & 0 & 0 & 0 \\ \text { V2d } & 0.92 & 0 & 0 & 0 & 0 & 0 & 0.08 \\ \text { V2v } & 0.99 & 0 & 0 & 0 & 0 & 0 & 0 \\ \text { V3A } & 0.95 & 0 & 0.05 & 0 & 0 & 0 & 0 \\ \text { V3d } & 0.92 & 0 & 0.08 & 0 & 0 & 0 & 0 \\ \text { V3v } & 1 & 0 & 0 & 0 & 0 & 0 & 0 \\ \text { V4dl } & 0.96 & 0 & 0.04 & 0 & 0 & 0 & 0 \\ \text { V4dm } & 0.24 & 0 & 0.76 & 0 & 0 & 0 & 0 \\ \text { V4v } & 0.92 & 0 & 0 & 0 & 0 & 0 & 0.06 \\ \text { 23c } & 0 & 0.96 & 0 & 0.04 & 0 & 0 & 0 \\ \text { 23d } & 0 & 0.33 & 0 & 0.55 & 0 & 0.06 & 0.06 \\ \text { 24ab } & 0 & 0 & 0 & 0 & 0 & 0 & 1 \\ \text { 24c } & 0 & 0 & 0 & 0 & 0 & 0 & 1 \\ \text { 24d } & 0 & 0.26 & 0 & 0.68 & 0 & 0.06 & 0 \\ \text { 25 } & 0 & 0 & 0 & 0 & 0.74 & 0 & 0.26 \\ \text { 29/30 } & 0 & 0 & 0 & 0.02 & 0 & 0 & 0.5 \\ 31 & 0 & 0.63 & 0.04 & 0.33 & 0 & 0 & 0 \\ \text { a24ab } & 0 & 0 & 0 & 0.29 & 0 & 0.17 & 0.54 \\ \text { a24c } & 0 & 0 & 0 & 0.06 & 0 & 0.38 & 0.56 \\ \text { d23ab } & 0 & 0 & 0 & 0.51 & 0 & 0.02 & 0.48 \\ \text { p24ab } & 0 & 0.01 & 0 & 0.94 & 0 & 0.06 & 0 \\ \text { p32 } & 0 & 0 & 0 & 0 & 0 & 0 & 1 \\ \text { s32 } & 0 & 0 & 0 & 0 & 0.08 & 0 & 0.92 \\ \text { v23ab } & 0 & 0 & 0 & 0 & 0 & 0 & 0.96 \\ \text { MT } & 0.07 & 0.09 & 0.21 & 0.11 & 0 & 0.09 & 0.44 \\ & & & & & & & \end{array}$


Supplementary Table 2: Incubation protocols.

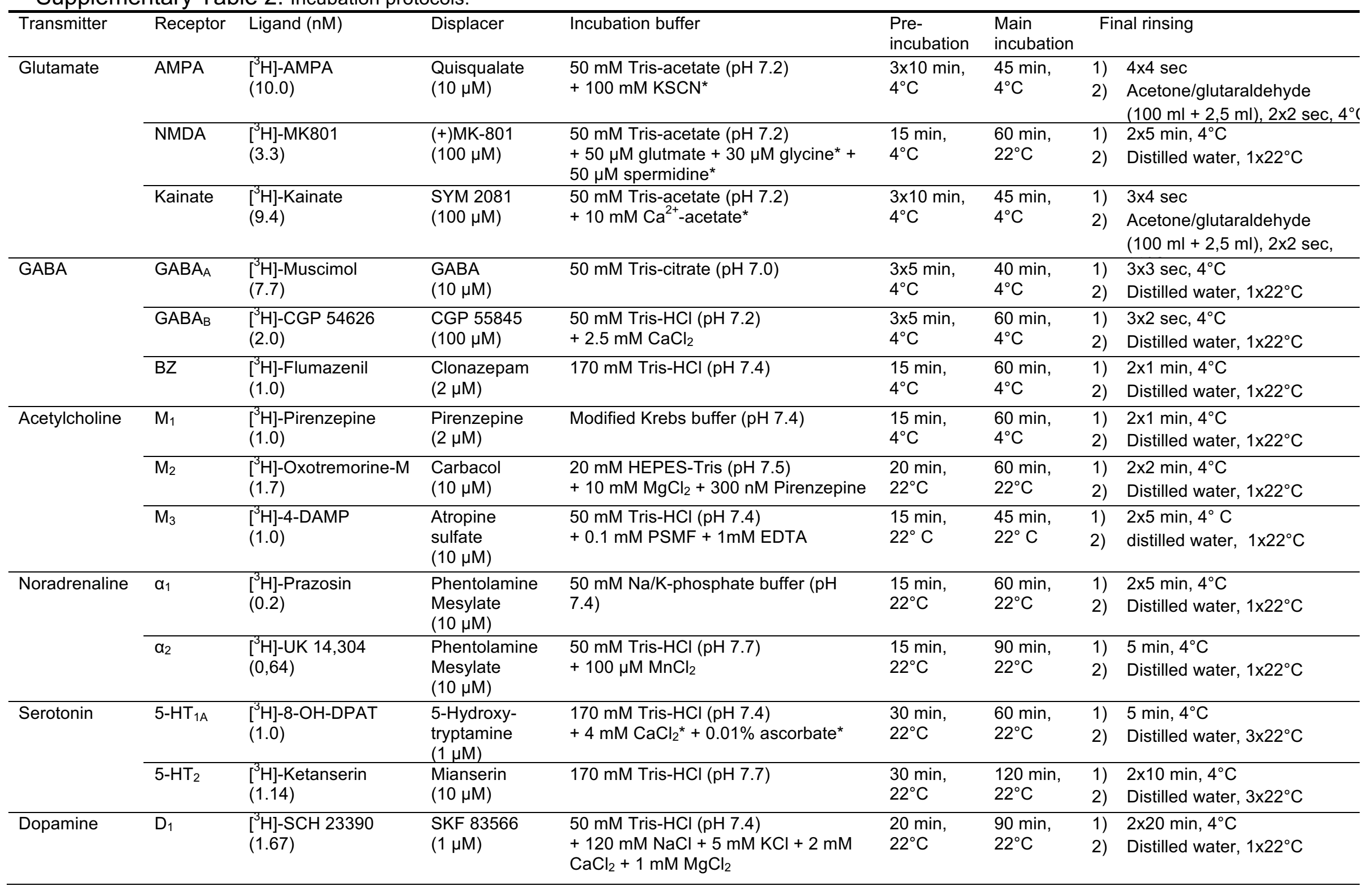


* Compound only included in buffer solution for the in the main incubation 